OECD Environment Working Papers No. 78

\title{
Greening Household Behaviour and Energy
}

Bengt Kriström, Chandra Kiran 


\section{Unclassified}

ENV/WKP(2014)16

Organisation de Coopération et de Développement Économiques

Organisation for Economic Co-operation and Development

16-Dec-2014

ENVIRONMENT DIRECTORATE

English - Or. English

Cancels \& replaces the same document of 12 December 2014

\section{ENVIRONMENT WORKING PAPER No. 78 - GREENING HOUSEHOLD BEHAVIOUR AND ENERGY}

By Bengt Kriström and Chandra Kiran (1)

(1) Umea-SLU University, Sweden.

OECD Working Papers should not be reported as representing the official views of the OECD or of its member countries. The opinions expressed and arguments employed are those of the author $(s)$.

Authorised for publication by Simon Upton, Director, Environment Directorate.

JEL Classification: C24, C25, C51, D11, D12, Q21, Q41, Q42, Q58

Keywords: Residential energy demand, energy efficiency, renewable energy, price premium, income elasticity, owner/renter split incentives, heterogeneity, soft vs hard policy instruments, energy investment, environmental attitudes, household survey.

OECD Environment Working Papers are available at www.oecd.org/env/workingpapers.htm

\section{JT03368634}

Complete document available on OLIS in its original format

This document and any map included herein are without prejudice to the status of or sovereignty over any territory, to the delimitation of international frontiers and boundaries and to the name of any territory, city or area. 


\section{OECD ENVIRONMENT WORKING PAPERS}

"OECD Working Papers should not be reported as representing the official views of the OECD or of its member countries. The opinions expressed and arguments employed are those of the author(s).

OECD Working Papers describe preliminary results or research in progress by the author(s) and are published to stimulate discussion on a broad range of issues on which the OECD works.

This series is designed to make available to a wider readership selected studies on environmental issues prepared for use within the OECD. Authorship is usually collective, but principal author(s) are named. The papers are generally available only in their original language -English or French- with a summary in the other language.

Comments on OECD Working Papers are welcomed, and may be sent to:

OECD Environment Directorate, 2, rue André Pascal, 75775 PARIS CEDEX 16, France or by e-mail to env.contact@oecd.org

OECD Environment Working Papers are published on www.oecd.org/env/workingpapers.htm

This document and any map included herein are without prejudice to the status of or sovereignty over any territory, to the delimitation of international frontiers and boundaries and to the name of any territory, city or area.

The statistical data for Israel are supplied by and under the responsibility of the relevant Israeli authorities. The use of such data by the OECD is without prejudice to the status of the Golan Heights, East Jerusalem and Israeli settlements in the West Bank under the terms of international law.

\section{(C) OECD (2014)}

You can copy, download or print OECD content for your own use, and you can include excerpts from OECD publications, databases and multimedia products in your own documents, presentations, blogs, websites and teaching materials, provided that suitable acknowledgment of OECD as source and copyright owner is given.

All requests for commercial use and translation rights should be submitted to rights@oecd.org 


\begin{abstract}
This report focuses on demand for renewable energy and energy efficiency. It presents the results of follow-up of econometric analysis of the 2011 OECD Survey on Environmental Policy and Individual Behaviour Change (EPIC). The report complements the overview of the survey data provided in the 2014 OECD publication "Greening Household Behaviour: Overview from the 2011 Survey".

The analysis shows that the level of willingness-to-pay (WTP) for renewable energy is driven primarily by non-economic factors, such as membership in an environmental organisation. Regarding energy efficiency, econometric analysis shows that owners are much more likely than renters to own energy efficient devices. Conditional on purchasing an energy efficient device, renters are as likely as owners to apply for a government grant (except windows and thermal insulation). The results indicate that increasing electricity prices tend to have a regressive impact. Multi-dwelling residences consume less energy than isolated ones, and so too do individuals who live in urban areas. Membership in an environmental organization and electricity consumption are negatively correlated. The literature surveyed, together with the analysis of the two rounds of the EPIC surveys (2008 and 2011), leads to several policy conclusions. Policy objectives should be made clear and allow for the fact that changes take time. Because policy impacts are typically heterogeneous across households, policy targeting may sometimes be useful. Policy advice must also take account of potential rebound effects to ensure that energy efficiency policies do not (unintentionally) increase energy demand.
\end{abstract}

JEL Classification: C24, C25, C51, D11, D12, Q21, Q41, Q42, Q58.

Keywords: Residential energy demand, energy efficiency, renewable energy, price premium, income elasticity, owner/renter split incentives, heterogeneity, soft vs hard policy instruments, energy investment, environmental attitudes, household survey. 


\section{RÉSUMÉ}

Ce rapport porte sur la demande d'énergie renouvelable et d'efficacité énergétique. Il présente les résultats de travaux d'analyse économétrique qui s'inscrivent dans le prolongement de l'enquête sur la politique de l'environnement et le comportement individuel (EPIC) réalisée par l'OCDE en 2011. Ce rapport complète la synthèse des données de l'enquête présentée dans l'ouvrage « Vers des comportements plus environnementaux: vue d'ensemble de l'enquête 2011 », OCDE (2014).

L'analyse des résultats de l'enquête montre que le niveau de consentement à payer (CAP) pour acheter de l'énergie renouvelable dépend principalement de facteurs non économiques, tels que l'appartenance à une organisation environnementale. S'agissant de l'efficacité énergétique, l'analyse économétrique montre que les propriétaires sont nettement plus susceptibles de posséder des appareils économes en énergie que les locataires. Parmi les acheteurs d'appareils éco-énergétiques, les locataires sont autant susceptibles que les propriétaires de demander une subvention publique (sauf pour les fenêtres et l'isolation thermique). Les résultats indiquent que l'augmentation des prix de l'électricité a généralement un impact régressif. L'habitat collectif consomme moins d'énergie que les habitations isolées, tout comme les individus vivant dans les zones urbaines. Enfin, l'appartenance à une organisation de protection de l'environnement et la consommation d'électricité sont corrélés de manière négative. Les études examinées et l'analyse des deux cycles EPIC (2008 et 2011) permettent de tirer plusieurs conclusions sur le plan de l'action. Les objectifs d'action doivent être énoncés clairement et tenir compte du fait que le changement prend du temps. Comme leurs effets sont généralement hétérogènes en fonction des ménages, le ciblage des politiques peut parfois être utile. Le conseil des politiques doit également prendre en compte les risques d'effets rebonds afin d'éviter que les politiques en faveur de l'efficacité énergétique entraînent (de manière non intentionnelle) une hausse de la demande d'énergie.

Classification JEL : C24, C25, C51, D11, D12, Q21, Q41, Q42, Q58.

Mots-clés: Demande d'énergie résidentielle, efficacité énergétique, énergies renouvelables, prime de prix, élasticité-revenu, propriétaire / locataire incitations divergentes, hétérogénéité, instruments politiques souples vs instruments politiques dures, investissement de l'énergie, attitudes envers l'environnement, enquête ménages. 


\section{TABLE OF CONTENTS}

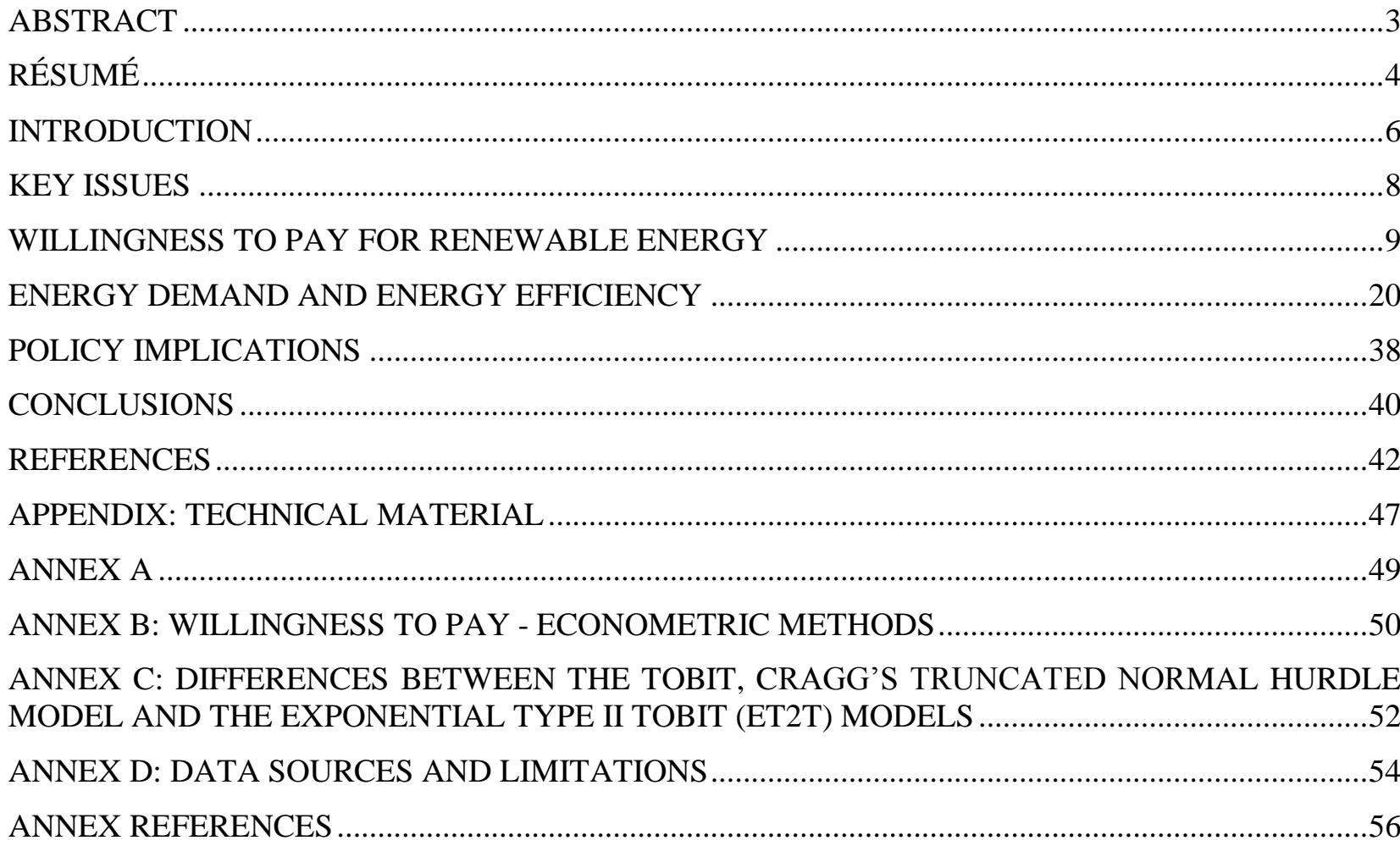

\section{Tables}

Table 1 Summary of recent studies on WTP for 'green' energy ............................................................... 10

Table 2 Effect of important covariates on probability of participation.....................................................14

Table 3 Effect of important determinants on mean WTP ..................................................................15

Table 4 Summary Statistics (mean) for Regression sample, disaggregated by Owner-Occupier and

Tenant

Table 5 Effect of home owning on different appliance/technology choices and on govt. grant applications

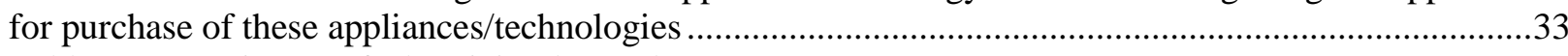

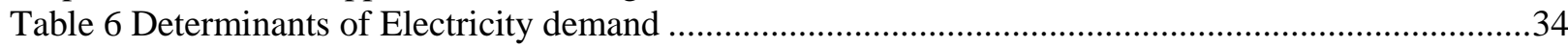

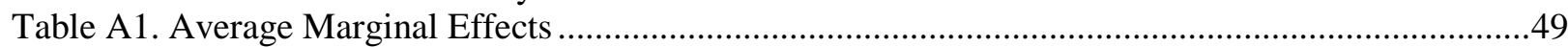

\section{Figures}

Figure 1 Average marginal effects from Censored QR for different variables. 


\section{INTRODUCTION}

The residential sector absorbs about one-fifth of total global energy demand to heat, cool, light and run appliances in residential dwellings (Brounen, Kok, and Quigley 2011). In the OECD, this sector consumes about one third of the electricity and heat services generated and it is increasing its share, as traditional industry is becoming less energy-intensive; use of electricity per capita in the sector rose from $1854 \mathrm{Kwh}$ in 1990 to $2456 \mathrm{Kwh}$ in 2010 . For industry, these two numbers are virtually the same (2427 Kwh vs. $2452 \mathrm{Kwh})^{1}$. In the EU-27, household final energy consumption rose by $0.41 \%$ per annum between 1990 and 2009 (de Almeida et al. 2011). Part of this final demand is generated by electricity, which is still dominantly generated by fossil fuels; electricity based on wind, solar and bioenergy comprises about $2 \%$ of the total while about $2 / 3$ of the world's electricity is based on fossil fuels (Borenstein 2012).Taken together, these facts suggest that the residential sector in the OECD will be an increasingly significant player in energy markets for years to come and there is little doubt it must be a key part of any comprehensive policy package that attempts to change the way we generate and use energy.

Countries continue to develop their environmental and energy policy in the sector. For example, the EU has recently sharpened its energy efficiency directive. Together with its triple 20 by 2020 initiative, this includes several measures directed towards residential energy use ${ }^{2}$. Overall, governments have, at least since the 1970s, used a range of energy and environmental policies to curb energy consumption. Whether or not these efforts have been successful, and what the best way forward is, remains a topic of debate ${ }^{3}$. Indeed, while there is substantial accumulated experience on the effectiveness of these policies in the sector $^{4}$, the verdict is still out on the most useful policies, not least because recent research has opened up new and potentially useful approaches.

This report attempts to shed some further light on energy and environment policy opportunities in the residential sector. By using the OECD 2011 survey on Environmental Policy and Individual Behaviour change (EPIC), and building upon the earlier work (OECD, 2011) as a springboard for a more detailed

\footnotetext{
${ }^{1}$ Source: International Energy Agency (2012). Electricity Information 2012. Paris, France: IEA Publications., population estimates are from http://esa.un.org/wpp/Excel-Data/population.htm

${ }^{2}$ The triple 20 by 2020 policy invoked by the EU includes, inter alia: (i) Establishing Annual Energy Efficiency Action Plans at national level (ii) Giving citizens better information (iii) Better targeting state aid where public support is justified (iv) Using public procurement to "kick-start" new energy efficient technologies (v) Going further regarding buildings. See http://re.jrc.ec.europa.eu/energyefficiency/pdf/MEMO-05-216_EN.pdf

${ }^{3}$ By way of illustrating the debates, Owens and Driffill (2008, p. 4413) provides a list of UK policies since the 1970s that they say "[have] been disappointing", in that "behaviors have been more energy-intensive". See Liddle (2012) for a contrary view. Furthermore, Gordon (2009) (p. 84) asserts that "there are massive number of allegations of neglected opportunities economically to reduce energy consumption. However, none of the proponents has experience in implementing energy choices..." In countering the informational failures argument, he writes (op.cit) "Consumers can readily determine the energy-use characteristics of all the energy-using equipment that they purchase".

${ }^{4}$ Gillingham, Newell, and Palmer (2009) estimated that the US conservation program they reviewed saved 4 quads of energy per year and reduce annual carbon emissions by up to 63 million metric tons $(4 \%)$. The bulk of these savings come from appliance standards, EPAs Energy Star program and some others. Observe that the system boundary seemingly does not include imports. Appliance standards "appear to be cost-effective "(p. 71) but other demand-side management programs are not as effective.
} 
analysis, we provide additional information about household behavior. In particular, the work reported in OECD (2014) used, for the most part, descriptive analysis, while this report uses a suite of more comprehensive statistical tools. We focus on two key pillars of a sustainable energy policy, i.e. energy efficiency and renewable energy, and only briefly touch upon distributional concerns, another important policy parameter in this context $\mathrm{t}^{5}$.

The 2011 EPIC survey is the second and latest round of the OECD household survey on environmental behaviour ${ }^{6}$. It was implemented in early 2011 and covered more than 12000 households in 11 countries: Australia, Canada, Chile, France, Israel ${ }^{7}$, Japan, Korea, the Netherlands, Spain, Sweden and Switzerland. The two rounds of the EPIC Survey were implemented using the Internet and responses to the questionnaire were collected by means of online household panels in different countries. For representativity, the sample was stratified in each country according to different parameters: age, gender, region and socio-economic groups ${ }^{8}$.

In brief, the paper does the following: it updates the previous review of the literature and applies a range of econometric models to the second round EPIC data. The analysis leads to a number of policy recommendations, backed by evidence culled from the extant literature and insights gathered within the OECD work on household behaviour. In more detail, the report has two main research objectives and one more general objective. First, the rapid development of the research literature necessitates an updated review of what we know about energy efficiency and willingness-to-pay for renewable energy in the residential sector. The most exciting developments have been in the energy efficiency literature and we place relatively more emphasis on this issue. Our second research objective is to develop appropriate econometric models to answer the key questions within the project. While formal econometric modeling brings a number of advantages relative to purely descriptive statistical analysis, it does not replace it, so this report and the analysis in the OECD publication "Greening Household Behaviour: Overview from the 2011 Survey" are truly complementary. The third objective is to try to combine insights from related research and the analysis of the EPIC data and arrive at a number of evidence-based policy recommendations.

We proceed as follows: Section 2 presents the key issues and the rest of the paper tries to address them; section 3 has results on willingness-to-pay for renewable energy, section 4 contains analysis of energy demand and energy efficiency, section 5 details policy recommendations and section 6 concludes. A technical appendix provides details about the econometric models used.

\footnotetext{
${ }^{5}$ See OECD (2006) for a survey of distributional issues in environmental policy making.

${ }^{6}$ The first EPIC survey was conducted in 2008 in 10 countries.

${ }^{7}$ The statistical data for Israel are supplied by and under the responsibility of the relevant Israeli authorities. The use of such data by the OECD is without prejudice to the status of the Golan Heights, East Jerusalem and Israeli settlements in the West Bank under the terms of international law.

${ }^{8}$ More details on the survey implementation are provided in (OECD, 2014). See Annex B.
} 


\section{KEY ISSUES}

This section pins down our key questions and our key dependent and independent variables to be used in the econometric analysis. Consider first our focal questions.

Our focal questions are:

- How much are households willing to pay to use only renewable energy? Are attitudes towards the environment a significant determinant of WTP for renewable energy? What are the characteristics of those respondents who are not willing to pay anything for renewable energy?

- Does individual electricity metering have significant effects on energy expenditures/consumption, investment in energy efficiency and behavioral practices?

- Who is likely to be most adversely affected by increases in residential energy prices?

- How do general attitudes towards the environment (environmental awareness; membership in environmental organisation) correlate with demand for energy efficient technologies and renewable energy?

- Who takes advantage of grants to invest in energy conservation? Who takes advantage of grants to install and use renewable energy?

- To what extent is demand for energy efficiency and renewable energy affected by special attributes of energy-related public services? (E.g. smart metering, time-differentiated electricity rates, option to select green tariff in electricity bill).

An important extension of our previous work is to account for outliers and missing data in a more comprehensive manner, especially in the case of expenditure and consumption data (where this is a significant issue). In particular, we develop econometric models that help unravel the importance of heterogeneity. This point can be explained with a very simple example. If a policy leads to a response from three different household groups as $(0,0,9)$, then traditional regression methods (loosely speaking) will show that the average response is 3 . The models we use here will help display the heterogeneity that we know exists in the data.

Discussions in the project with member country representatives and frameworks suggested in the literature, has led to a narrowing down on key drivers. These are used in the econometric models and comprise: Economic (income levels, education, and job status), demographic (household size and composition, age, and urban rural), residential characteristics (detached vs. multi-dwelling etc.) and attitudinal characteristics (general environmental attitudes and perception of environmental concerns). 


\section{WILLINGNESS TO PAY FOR RENEWABLE ENERGY}

This section begins, after explaining the basic framework, with a compact update of the literature and then proceeds with econometric modeling. The modeling part sets out two distinct ideas, both which have been studied quite intensively in other economic literatures, but remains somewhat understudied in the literature on valuation of environmental services. First, we consider the decision to pay in a two-stage fashion; the consumer first decides if it is worthwhile entering the (hypothetical) market and then, given entry, how much to pay. These "entry" and "level" decisions are not necessarily driven by the same factors, a fact we exploit in the econometric modeling. Second, we use recently developed quantile regression methods to obtain information at different points of the distribution. In this way, we can get a picture of how various background variables affect WTP at, say, "low", "intermediate" and "high values" of WTP (in principle, we can obtain the impacts at all quantiles of the estimated distribution) ${ }^{9}$. In both cases, we will investigate, as far as possible, the consequences of missing data.

\section{$1 \quad$ Framework}

Our primary objective is to measure how much households are willing-to-pay (WTP), at the maximum, for having an energy system in which electricity generation is based only on renewables. For most countries in the world, this is an unrealistic proposition in the short term for the total consumption of the residential sector. However, understanding preferences at the level of the individual household for such a 'rebalancing' of input choices provides useful policy guidance. Moreover, from an individual point of view, paying a premium for "green energy" is not unfamiliar in the electricity market because many companies actually offer to sell "green electricity" at a price premium. This resemblance with a private market is convenient when eliciting WTP in the questionnaire, even though the scenario is hypothetical.

We thus elicit WTP by asking for the maximum percentage increase of the electricity bill the individual could sustain, in return for obtaining energy based only on renewables. Observe that this construction finesses the thorny problem of comparing different currencies. Furthermore, while the individual selects to buy "green energy" in the market if his WTP exceeds the price, it is important to reiterate that we are trying to measure the critical price, the maximum the individual could afford to go beyond observing that households would like to contribute something towards the suggested project.

Finally, the individual is asked to consider the value of "re-mixing" current electricity consumption, such that the same number of Kwh is guaranteed to come from renewable sources only. In this way, we know that the value the individual place on this scenario is only related to the new mix and not to how many Kwh is consumed (this is in contrast to most studies in this literature).

And finally, while it would be interesting to obtain information on WTP for different individual renewable energy choices (i.e. wind, solar, tidal/marine, biomass, etc...) for reasons of parsimony demand for different renewables was treated indiscriminately.

It might be useful to place the results to be presented from this survey within the extant literature. In the next section, we provide a compact summary of the literature on the price-premium. We refer to OECD (2011 and 2014) for details; we focus here on contributions mainly after 2009.

\section{Literature review}

There is now a substantial literature on the value households place on an energy system based on renewable energy. Such information is potentially useful for policy-making in that it gives a benchmark when contemplating the benefits and the costs of expanding renewable energy sources. Even so, it should be clear at the outset that the EPIC surveys are not intended to be formal contingent valuation studies, the

\footnotetext{
${ }^{9}$ Quantile regression is getting increasingly popular also in the literature on residential energy demand, as witnessed by the papers in the designated sessions on household behavior at 2012 EAERE conference in Prague.
} 
traditional tool used when valuing environmental quality. Such an endeavor is simply not feasible. Table 1 provides a summary of some of the most recent literature.

Table 1 Summary of recent studies on WTP for "green" energy

\begin{tabular}{|c|c|c|c|c|c|c|c|}
\hline Author & Country & Method & $\begin{array}{l}\text { Dependent } \\
\text { variable }\end{array}$ & Demographics & Economics & Attitudes & Others \\
\hline $\begin{array}{l}\text { Yoo and } \\
\text { Kwak, } 2009\end{array}$ & Korea & Spike model & $\begin{array}{l}\text { Whether willing to } \\
\text { pay for green } \\
\text { electricity policy }\end{array}$ & & $\begin{array}{l}\text { Bid }(-) \\
\text { Income }(+)\end{array}$ & & \\
\hline $\begin{array}{l}\text { Gerpott and } \\
\text { Mahmudova, } \\
2010\end{array}$ & Germany & $\begin{array}{l}\text { Partial least } \\
\text { squares } \\
\text { analysis }\end{array}$ & $\begin{array}{l}\text { 5-scale agreement } \\
\text { to willing to adopt } \\
\text { green electricity }\end{array}$ & & & $\begin{array}{l}\text { Social endorsement }(+) \\
\text { Environmental } \\
\text { protection attitude }(+)\end{array}$ & $\begin{array}{l}\text { Switching } \\
\text { difficulty (-) }\end{array}$ \\
\hline $\begin{array}{l}\text { Gerpott and } \\
\text { Mahmudova, } \\
2010\end{array}$ & Germany & $\begin{array}{l}\text { Logistic } \\
\text { regression } \\
\text { Ordinal } \\
\text { regression }\end{array}$ & $\begin{array}{l}\text { Six-rank willing to } \\
\text { pay a mark-up for } \\
\text { green electricity }\end{array}$ & $\begin{array}{l}\text { Household } \\
\text { size }(+) \\
\text { Age }(-)\end{array}$ & $\begin{array}{l}\text { Electricity } \\
\text { bill(-) }\end{array}$ & $\begin{array}{l}\text { Attitude towards } \\
\text { environment and } \\
\text { current supplier }(+) \\
\text { Social reference } \\
\text { group }(+)\end{array}$ & $\begin{array}{l}\text { Ecological } \\
\text { conservation } \\
\text { behavior(+) }\end{array}$ \\
\hline Ozaki, 2011 & UK & $\begin{array}{l}\text { Correlation } \\
\text { analysis }\end{array}$ & $\begin{array}{l}5 \text {-scale } \\
\text { agreement to } \\
\text { adoption intention }\end{array}$ & & & $\begin{array}{l}\text { Attitude towards green } \\
\text { electricity }(+) \\
\text { Social influence }(+) \\
\text { Normative beliefs }(+) \\
\text { Controllability }(+) \\
\text { Information }(+)\end{array}$ & \\
\hline $\begin{array}{l}\text { Oliver et al. } \\
2011\end{array}$ & $\begin{array}{l}\text { South } \\
\text { Africa }\end{array}$ & $\begin{array}{l}\text { Logistic } \\
\text { regression }\end{array}$ & $\begin{array}{l}\text { Willing to pay a } \\
\text { premium for green } \\
\text { electricity }\end{array}$ & & Income (+) & $\begin{array}{l}\text { Reliable attitude }(+) \\
\text { Everyone should } \\
\text { contribute }(+)\end{array}$ & $\begin{array}{l}\text { Recycle } \\
\text { behavior(+) }\end{array}$ \\
\hline Hansla, 2011 & Sweden & OLS & $\begin{array}{l}\text { Five-scale } \\
\text { likelihood to pay a } \\
\text { surcharge for eco- } \\
\text { labeled electricity }\end{array}$ & & $\begin{array}{l}\text { Surcharge(- } \\
\text { ) }\end{array}$ & $\begin{array}{l}\text { Biospheric framing }(+) \\
\text { Self-transcendence } \\
\text { value }(+)\end{array}$ & \\
\hline $\begin{array}{l}\text { Abdullah and } \\
\text { Jeanty, } 2011^{10}\end{array}$ & Kenya & $\begin{array}{l}\text { Double } \\
\text { bounded } \\
\text { model }\end{array}$ & $\begin{array}{l}\text { Whether willing to } \\
\text { pay for PV } \\
\text { electricity }\end{array}$ & $\begin{array}{l}\text { Owner- } \\
\text { occupier (+) } \\
\text { Age(-) }\end{array}$ & $\begin{array}{l}\text { Income }(+) \\
\operatorname{Bid}(-)\end{array}$ & $\begin{array}{l}\text { Interested in } \\
\text { business }(+)\end{array}$ & \\
\hline $\begin{array}{l}\text { Zoric and } \\
\text { Hrovatin, } \\
2012^{11}\end{array}$ & Slovenia & $\begin{array}{l}\text { Tobit and } \\
\text { Double } \\
\text { hurdle model }\end{array}$ & $\begin{array}{l}\text { Willingness to pay } \\
\text { for green } \\
\text { electricity }\end{array}$ & Age(-) & $\begin{array}{l}\text { Income }(+) \\
\text { Electricity } \\
\text { bill(+) }\end{array}$ & $\begin{array}{l}\text { Environmental } \\
\text { awareness(+) }\end{array}$ & \\
\hline $\begin{array}{l}\text { Strazzera, et } \\
\text { al. } 2012\end{array}$ & Italy & $\begin{array}{l}\text { Double } \\
\text { bound model }\end{array}$ & $\begin{array}{l}\text { Whether willing to } \\
\text { pay a bid for solar } \\
\text { energy }\end{array}$ & $\begin{array}{l}\text { Urban(+) } \\
\text { In energy } \\
\text { sector(+) } \\
\text { Home green } \\
\text { tech(+) }\end{array}$ & Bill(+) & $\begin{array}{l}\text { Health risk } \\
\text { perception(+) } \\
\text { Photovoltaic pollution } \\
\text { perception(-) } \\
\text { Invest heavy } \\
\text { industry(+) }\end{array}$ & $\begin{array}{l}\text { Coal } \\
\text { information(+) } \\
\text { Contact } \\
\text { Energy } \\
\text { Agency (+) }\end{array}$ \\
\hline Liu et al. 2012 & China & Logit model & $\begin{array}{l}\text { Positive } \\
\text { willingness to pay } \\
\text { for renewable } \\
\text { energy }\end{array}$ & Age(-) & Income (+) & $\begin{array}{l}\text { Belief about the cost(+) } \\
\text { Knowledge }(+)\end{array}$ & \\
\hline $\begin{array}{l}\text { Ertör-Akyazi et } \\
\text { al. } 2012\end{array}$ & Turkey & Logit model & $\begin{array}{l}\text { Endorsement of } \\
\text { renewable energy }\end{array}$ & Education(+) & & $\begin{array}{l}\text { Knowledge of climate } \\
\text { change }(+) \\
\text { Environmental } \\
\text { optimism (-) } \\
\text { Environmental } \\
\text { concern(+) } \\
\text { Economy-oriented(-) }\end{array}$ & \\
\hline $\begin{array}{l}\text { Zhai and } \\
\text { Williams, } 2012\end{array}$ & US & $\begin{array}{l}\text { Fuzzy logit } \\
\text { model }\end{array}$ & $\begin{array}{l}\text { Adoption of } \\
\text { photovoltaic }\end{array}$ & & & $\begin{array}{l}\text { Environmental } \\
\text { concern(+) } \\
\text { Perceived cost of solar } \\
\text { panels(-) } \\
\text { Perceived maintenance } \\
\text { requirement(-) }\end{array}$ & \\
\hline
\end{tabular}

First, note that the studies cover a substantial number of countries, including developed and developing countries. Second, researchers involved in this literature represent a fairly wide set of

${ }^{10}$ The result is for photovoltaic of monthly payment.

${ }^{11}$ These factors influence the amount of WTP. The decision of participation is determined by age, education, and environmental awareness. 
disciplines from various parts of the social sciences. Third, the choice of statistical approach vary somewhat, but there is a preponderance of papers using econometric methods such as Logit and Tobit.

Oliver, Volschenk, and Smit (2011) is one of the recent studies that bring in developing country perspectives. Employing a random sample of 543 households in the Cape Peninsula (SA), they use correlation and logit analysis to test a number of hypotheses. A key finding is that income correlates positively with WTP. We will come back to this finding, because income can affect the decision to adopt and how much to pay in different ways. Abdullah and Jeanty (2011) considers the value Kenyans (in the Kisimu district) place on electricity connection in rural areas. They find that respondents place a higher value on grid connection services compared to a Photovoltaic alternative, leading the authors to propose inter alia - subsidies for electricity connections. Liu et al (2012) uses a survey of respondents in Shandong and confirms several other studies in that income is positively related to WTP, as has knowledge. However, age has a negative impact.

Turning now to a few examples of recent studies with from EU countries, we begin with a study by Gerpott and Mahmudova (2010), who uses a survey of 238 German households to find that roughly half $(53.5 \%)$ are "in-the-market" for "green energy", while 26.1\% support a price premium in the range 5-10\%. These figures are similar to what we found in the EPIC surveys, as is the finding that attitudes towards the environment play a significant role for WTP. Ozaki (2011) asks a somewhat different question in her survey of 103 UK respondents; she looks at the switching, or adoption, decision from a sociology standpoint. She reports at least one surprising result, given that the sample had (according to the author) a "green bias";

“... we found great hesitation among them [the respondents] about adopting a green electricity tariff, and even those with high adoption intentions are indecisive. Positive green attitudes towards pro-environmental behaviors do not necessarily translate into the performance of the behaviors." (p.14)

The reasons why "green" consumers do not automatically/necessarily switch to "green" electricity include, according to Ozaki (2011), switching costs (in general terms), uncertainty about the quality of green energy and the lack of strong social norms. (For more on norms in this context see Ek and Söderholm 2008 and 2010). The switching inconvenience referred to by Ozaki's (2011) respondents appears to be directly related to the "hidden costs" economists apply to explain tardiness in switching to more energy saving technology.

Hansla (2011) presents a study based on psychological theories, employing a sample of 1800 Swedes (with a $26.5 \%$ response rate). Respondents were shown five different price premiums and asked how likely they would make the switch for each premium. Hansla (2011) used different "treatments" for subsamples. The study gave some support for the idea that altruism positively affects the probability of paying the premium. We will come back to this finding when we discuss energy efficiency, given that social context and involvement have important effects in that area. Zhai and Williams (2012) scrutinize adoption of photovoltaics (PV), using a survey of 487 homeowner-occupiers in Phoenix (of which 21 had already installed a grid connected PV). The authors claim that it is not only the direct economic consequences that are important determinants of adoption, but maintenance and environmental awareness also plays a role. As a final example of recent research in this area, Strazzera, Mura, and Statzu (2012) split a sample of 358 individuals in the province of Oristano, Italy, such that one subsample is asked about coal and solar, the other subsample is asked about the same energy sources but in the reverse order. The contingent valuation study attempted to find out: a) the (negative) value of coal, and; b) the value of renewables. In the case of coal, the respondents were offered a price that would save on their utility bill, should they switch to this particular technology. In the case of renewables, the respondent was given a price-premium to accept or reject that would entail receiving all electricity from solar energy. The average 
discount accepted is $64 \%$ of the annual bill for the switch to only coal, while the switch to only solar is valued at $40 \%$ surcharge on the existing bill.

Zorić and Hrovatin (2012) employ a final sample of 450 Slovenian households and use econometric methods similar to the ones in this OECD project, to find that income is a significant driver of WTP. They find an average WTP of about 9\% increase of the monthly bill, which is comparable to the one we present in our analysis below. This could be the result of subsidised electricity in Slovenia (Zoric and Hrovatin, 2012 , p. 184)). Interestingly, they find that income is positively related to the level of WTP, but not significant for the participation decision, a result opposite of what we find here (see below). Ertör-Akyazı et al. (2012) look at preferences for nuclear and renewable energy in Turkey, using a sample of 2248 urban Turks. The logit model used shows that endorsement of renewable energy is positively related to education and environmental concern, while "economy-oriented" individuals were less likely to endorse renewable energy.

If we compare these new contributions to the literature to our review in OECD (2011), some of the conclusions made then are not challenged by new findings. These include the importance of environmental attitudes and income, but note that we here try to differentiate between an income effect of entering the market and the effect of income on the level of WTP. Consistent with the findings reported below, the most recent studies (allegedly only a few) do report WTP higher estimates than we found earlier in the EPIC survey. Market research demonstrates that the extractable price premium is only a few percentage points; we found an average of about $4 \%$ in the previous survey, and this is upped to almost $10 \%$ in this survey (see OECD 2014). Comparability issues (studies use different elicitation mechanism, different scenarios etc.) make it difficult to make much of this finding. Still, the valuations are somewhat higher in more recent studies.

\section{$3 \quad$ Econometric analysis}

We turn now to understanding pertinent drivers of WTP for "green" energy. As noted, our econometric modelling is based on a two-step framework and it differs from that used in the existing literature in important ways. First, we model the two-step process in significantly more detail and allow for different assumptions regarding how households make these decisions. Secondly, because standard models (e.g. Tobit) focus on the mean ${ }^{12}$, they cannot handle unobserved or non-additive heterogeneity, we use more flexible censored quantile regression method (CQR), recently developed in Chernozhukov, Fernández-Val, and Kowalski (2011). This method allows for heterogeneity and corner solutions (i.e. zero $(\mathrm{WTP})^{13}$.

Two sets of empirical results are provided. First, the results from several commonly used parametric methods (see Appendix for details regarding these models, and especially for a comparison of the assumptions made for each); a simple Tobit, Cragg's Tobit (so-called "hurdle models") and the so-called Exponential type II Tobit (ET2T). The ET2T, being more flexible than both the Tobit and the hurdle

\footnotetext{
${ }^{12}$ To be precise, this is the conditional mean $\mathrm{E}(W T P \mid X, W T P>0)$

${ }^{13}$ In addition, given the well-known tendency of commonly used censored and binary regression models to be highly sensitive to heteroscedasticity, CQR is an ideal choice, when interpreted as a heteroscedasticity-robust censored regression framework. Quantile regressions were initially developed as a location-scale generalization of commonly used regression frameworks, which allowed only the location of the distribution to vary with covariates. See Koenker (2005) for more details on this interpretation. Note that the Wald test framework used in our setting, the test is essentially one of location-scale versus locationonly models.
} 
models, is chosen as the preferred conditional mean model ${ }^{14}$. Second, preliminary results from the QR method for corner solutions are presented, and the differences in such results are illustrated.

\subsection{Tobit-style models}

The covariates of interest are taken to be: an indicator for environmental membership, an indicator for being resident of a city, an indicator for being a professional, a measure of stated income and an energy behaviour index. Many of these variables are likely to be important non-income indicators of attitudes which may substantially impact WTP. Conditional on these, a higher "score" on the Energy behaviour index (higher scores being associated with greater awareness regarding/or utility of energy saving activities) suggests a higher WTP ${ }^{15}$. Results are presented in Tables 2 and 3.

${ }^{14}$ The ET2T model is more flexible than the hurdle models, since the unobserved drivers of the "participation" and "amount" decisions are allowed to be related, an important advantage in the case of the current application. In addition, this model also shares features of the hurdle models (e.g. allowing covariates to exert different direction of impact upon the "participation" and "amount" decision) which make them more flexible than the Tobit model. More details are to be found in Annex B and C.

${ }^{15}$ The three continuous variables, $\log$ (income), various versions of WTP (raw values, positive values and $\log$ of positive values) have very little correlation for such an issue to be of any concern. Most models here are non-linear, further modulating such concerns. Finally, dropping log (home size) has no impact on the estimates of other coefficients. 
Table 2 Effect of important covariates on probability of participation

\begin{tabular}{|c|c|c|c|}
\hline & Tobit & Hurdle Model & ET2T \\
\hline \multirow[t]{2}{*}{ log(household income) } & 0.024 & $0.043^{\star *}$ & $0.053^{* * *}$ \\
\hline & $(1.578)$ & $(2.500)$ & $(3.474)$ \\
\hline \multirow[t]{2}{*}{ Member of Envt. Organisation } & $0.159^{* * *}$ & $0.142^{* * *}$ & $0.144^{\star * \star}$ \\
\hline & $(7.102)$ & $(4.534)$ & $(5.288)$ \\
\hline \multirow[t]{2}{*}{ Energy Behaviour Index } & -0.005 & -0.008 & -0.005 \\
\hline & $(-1.033)$ & $(-1.530)$ & $(-0.974)$ \\
\hline \multirow[t]{2}{*}{ Index of Concern for CC } & $-0.009^{* *}$ & $-0.016^{* \star *}$ & $-0.009^{\star *}$ \\
\hline & $(-2.294)$ & $(-3.443)$ & $(-1.990)$ \\
\hline \multirow[t]{2}{*}{$\log ($ home size) in m2 } & $0.041^{* *}$ & 0.033 & $0.040^{* *}$ \\
\hline & $(2.418)$ & $(1.548)$ & $(2.059)$ \\
\hline \multirow[t]{2}{*}{ Members in household } & $0.015^{\star \star \star}$ & $0.019^{* \star *}$ & $0.011^{*}$ \\
\hline & $(2.599)$ & $(2.586)$ & $(1.653)$ \\
\hline \multirow[t]{2}{*}{ Length of stay at residence (years) } & -0.009 & $-0.020^{\star *}$ & -0.009 \\
\hline & $(-1.364)$ & $(-2.342)$ & $(-1.110)$ \\
\hline \multirow[t]{2}{*}{ Home Type (1=Multi-dwelling) } & 0.024 & 0.031 & 0.025 \\
\hline & $(1.416)$ & $(1.424)$ & $(1.258)$ \\
\hline \multirow[t]{2}{*}{ Urban (1=Yes) } & 0.005 & 0.009 & -0.002 \\
\hline & $(0.329)$ & $(0.452)$ & $(-0.131)$ \\
\hline \multirow[t]{2}{*}{ Age of $\mathrm{HH}$ head } & $-0.001^{* *}$ & 0.001 & $-0.002^{* * *}$ \\
\hline & $(-2.358)$ & $(0.989)$ & $(-3.264)$ \\
\hline \multirow[t]{2}{*}{ Years of Post-Secondary Education } & $0.013^{\star * *}$ & $0.013^{\star * *}$ & $0.010^{\star \star \star}$ \\
\hline & $(3.738)$ & $(3.487)$ & $(2.737)$ \\
\hline \multirow[t]{2}{*}{ Gender(1=Male) } & 0.011 & 0.009 & \\
\hline & $(0.797)$ & $(0.534)$ & \\
\hline \multirow[t]{2}{*}{ Marital Status (1=Married/staying together) } & -0.025 & $-0.058^{* * *}$ & \\
\hline & $(-1.534)$ & $(-2.774)$ & \\
\hline \multirow[t]{2}{*}{ Employment Status (1=Employed) } & -0.002 & -0.028 & \\
\hline & $(-0.143)$ & $(-1.473)$ & \\
\hline \multirow[t]{2}{*}{ Gender (encoded) } & & & $-0.047^{* * *}$ \\
\hline & & & $(-2.963)$ \\
\hline Observations & 7789 & 7789 & 9386 \\
\hline
\end{tabular}

${ }^{*} p<0.1{ }^{* *} p<0.05^{* * *} p<0.01$

Notes: Table reports average marginal effects (AME's) on probability of "participation", i.e. $\frac{\partial P(y>0 \mid X)}{\partial X_{j}}$, from different models, with tstatistics in parentheses. For binary variables, the AME are the differences between the two categories of the independent variable. The Hurdle model has a first stage probit, and so the AME are those from a simple probit. The ET2T and Tobit are two stage models, and therefore, the number of observations used is the same as those for the marginal effects of the conditional mean. All regressions include country-fixed effects (not reported) and account for the complex survey nature (i.e. use probability weights for estimation). 


\begin{tabular}{|c|c|c|c|c|}
\hline & OLS & Tobit & Hurdle Model & ET2T \\
\hline \multirow[t]{2}{*}{ Log(household income) } & -0.398 & 0.876 & -0.370 & 0.031 \\
\hline & $(-0.500)$ & $(1.574)$ & $(-0.487)$ & $(0.730)$ \\
\hline \multirow[t]{2}{*}{ Member of Envt. Organisation } & $6.192^{* * *}$ & $5.903^{* * *}$ & $5.117^{\star \star \star}$ & $0.334^{* * *}$ \\
\hline & $(4.860)$ & $(7.011)$ & $(5.559)$ & $(5.610)$ \\
\hline \multirow[t]{2}{*}{ Energy Behaviour Index } & 0.073 & -0.173 & 0.083 & 0.008 \\
\hline & $(0.279)$ & $(-1.033)$ & $(0.319)$ & $(0.556)$ \\
\hline \multirow[t]{2}{*}{ Index of Concern for CC } & 0.110 & $-0.332^{* *}$ & 0.089 & 0.002 \\
\hline & $(0.527)$ & $(-2.287)$ & $(0.430)$ & $(0.194)$ \\
\hline \multirow[t]{2}{*}{ Log (home size) in $\mathrm{m} 2$} & $1.836^{\star \star}$ & $1.529^{\star \star}$ & $1.689^{*}$ & 0.063 \\
\hline & $(2.029)$ & $(2.411)$ & $(1.879)$ & $(1.210)$ \\
\hline \multirow[t]{2}{*}{ Members in household } & 0.236 & $0.561^{* * *}$ & 0.270 & 0.020 \\
\hline & $(0.775)$ & $(2.607)$ & $(0.929)$ & $(1.173)$ \\
\hline \multirow[t]{2}{*}{ Length of stay at residence (years) } & 0.287 & -0.343 & 0.261 & 0.012 \\
\hline & $(0.753)$ & $(-1.365)$ & $(0.678)$ & $(0.535)$ \\
\hline \multirow[t]{2}{*}{ Home Type (1=Multi-dwelling) } & 0.582 & 0.895 & 0.467 & 0.030 \\
\hline & $(0.635)$ & $(1.418)$ & $(0.520)$ & $(0.573)$ \\
\hline \multirow[t]{2}{*}{ Urban $(1=$ Yes $)$} & 0.043 & 0.197 & 0.159 & -0.025 \\
\hline & $(0.048)$ & $(0.329)$ & $(0.178)$ & $(-0.481)$ \\
\hline \multirow{2}{*}{ Age of $\mathrm{HH}$ head } & $-0.167^{\star \star \star}$ & $-0.053^{\star *}$ & $-0.182^{\star * *}$ & $-0.009^{\star * *}$ \\
\hline & $(-5.116)$ & $(-2.353)$ & $(-5.047)$ & $(-4.509)$ \\
\hline \multirow[t]{2}{*}{ Years of Post-Secondary Education } & $0.319^{*}$ & $0.466^{\star * *}$ & $0.335^{*}$ & $0.019^{*}$ \\
\hline & $(1.721)$ & $(3.711)$ & $(1.771)$ & $(1.818)$ \\
\hline \multirow[t]{2}{*}{ Gender (1=Male) } & 0.424 & 0.421 & 0.353 & $-0.095^{\star}$ \\
\hline & $(0.547)$ & $(0.797)$ & $(0.450)$ & $(-1.698)$ \\
\hline \multirow[t]{2}{*}{ Marital Status ( $1=$ Married/staying together) } & 1.105 & -0.946 & 1.347 & 0.045 \\
\hline & $(1.204)$ & $(-1.534)$ & $(1.438)$ & $(0.848)$ \\
\hline \multirow[t]{2}{*}{ Employment Status (1=Employed) } & 1.388 & -0.083 & $1.713^{*}$ & 0.045 \\
\hline & (1.628) & $(-0.143)$ & $(1.891)$ & $(0.912)$ \\
\hline Observations & 5079 & 7789 & 5079 & 9386 \\
\hline
\end{tabular}

${ }^{*} p<0.1{ }^{* *} p<0.05{ }^{* *} p<0.01$

Notes:Table reports average marginal effects (AME's), $\frac{\partial \mathrm{E}(y \mid X, y>0)}{\partial X_{j}}$, with t-statistics in parentheses, from four separate

regressions for the conditional mean(see text for details on method). The number of observations differs by method, with all two-step estimators using more observations, depending upon included covariates. All regressions include country-fixed effects (not reported) and account for the complex survey nature (i.e. use probability weights for estimation).

Consider first the effect of income on participation; income positively impacts the probability of participation, with a substantial increase $(4.3 \%$ to $5.3 \%)$ in probability of participation, in the more realistic 
models (ET2T and hurdle). However, income has no statistically significant impact once an individual is "in the market" on the amount he/she is willing to pay. We return to this issue below. An important nonmonetary measure, membership in an environmental organization, impacts both participation and amount. These results are consistent with earlier findings using less powerful approaches; see $\operatorname{OECD}(2011,2014)$. In addition, we find that the index of concern for climate change has an impact on the participation decision in our preferred model (ET2T), but not in terms of the valuation level.

A proxy for disposable income, household size, appears to positively affect participation but has no discernible impact on the level of valuation decision. In our preferred model, the ET2T, age is positively related to both the amount and participation decision. One possible reason for this atypical result is that the respondents are relatively young, even after correcting for sampling bias. Education is likely to both increase participation probability and conditional on participation, the price premium. Gender does not seem to have a substantial effect on participation; there is weak evidence, in our preferred model at least, of the usual gender effect, with men having a lower WTP, conditional on participation, than do women.

We do not detect any significant rural-urban divide and nor do we detect significant differences between those who live in apartments and those in isolated dwellings. Similarly, employment and marital status appear not to affect either participation or amount of WTP, conditional on other characteristics.

In summary, income is a significant determinant of participation in the "green energy" market. On the other hand, conditional on participation, attitudinal factors such as membership of an environmental organization and individual-specific factors, proxied by age and years of education, are important determinants of the amount of WTP. In particular, in our preferred model, we find that the income elasticity of WTP is insignificant. These findings are buttressed by our previous work on the EPIC survey. But observe that we are implicitly discussing an "average" effect and we will now develop a model that allows a more comprehensive picture.

\subsection{Censored quantile regressions}

Quantile regression (QR) is increasingly being used in economic analysis to better understand potential heterogeneity. We present the results in the form of a graph, a convenient and widely used way for visualizing the variation in coefficients or effects across a range of quantiles. Theory typically provides little guidance for which, and how many, quantiles to estimate; in empirical studies therefore, a wide range of quantiles are estimated, a practice which we follow by estimating a range of conditional quantiles, from the $20^{\text {th }}$ percentile to the $90^{\text {th }}$, with increments of 5 percentiles ${ }^{16}$. The regressions at each of these quantiles were independently estimated, along with confidence intervals; these independent estimates were then plotted $^{17}$.

\footnotetext{
${ }^{16}$ There were issues with estimation of quantiles below the $20^{\text {th }}$, particularly between the $10^{\text {th }}$ and $20^{\text {th }}$ as a result of which, we report results only from the $20^{\text {th }}$. Also, with a relatively small, for quantile regression, sample size (of about 9000), estimation far into the tails is typically fraught with uncertainty, as a result of which we do not proceed beyond the $90^{\text {th }}$, or below the $10^{\text {th }}$, percentile.

${ }^{17}$ Unlike the case of density (distribution) function estimation, the curve itself is not directly estimated; the graphical presentation is intended to provide a visual representation of variation in the coefficients, rather than an estimate of the quantile function.
} 
Analysis (not reported) indicates that the overall quantile process is significant, and most coefficients differed across quantiles ${ }^{18}$; this means that the response of a certain background depends on the level of $\mathrm{WTP}^{19}$.

Recall that the conditional mean estimates indicated that income had an insignificant effect on the amount decision, but played a substantial part in the participation decision. Income, in the QR setting, is never significant across the entire range of quantiles. However, our proxy of total household disposable income, household size, is positively related to WTP, but only (marginally) significant at the middle regions of the distribution of WTP. We see a similar result with the conditional mean models, with disposable income only being a significant factor for the participation decision.

A recurrent theme in our work on the EPIC surveys has been the importance of membership in an environmental organization in understanding WTP (and other variables). Our QR approach strengthens this finding and unravels another feature, see figure 1.

${ }^{18}$ There is a relatively simple goodness-of-fit measure, a LR-like statistics; however, in most cases, there is no simple interpretation of such a statistics and its use is deprecated. Especially in this case, with probability weighting, it is not clear what the distribution of such a statistic is and how to interpret it. We do not therefore pursue that approach. We carry out instead the following Wald tests: $\boldsymbol{\beta}(\tau)=\boldsymbol{\beta}, \forall \tau$, a test for parameter equality across quantiles and $\boldsymbol{\beta}(\tau)=0$, for each $\tau$, a test for "model significance" at the $\tau^{\text {th }}$ quantile, with $\boldsymbol{\beta}$ a vector of coefficients. There is no analogous test for marginal effects in the quantile setting; therefore, all "significance" results relate to those using tests on coefficients.

${ }^{19}$ While we will contrast the results obtained with the CQR framework with those obtained using the conditional mean models, the results are not, strictly speaking, directly comparable since the modeling frameworks are rather different, especially in the censored regression case. 
Figure 1 Average marginal effects from Censored QR for different variables
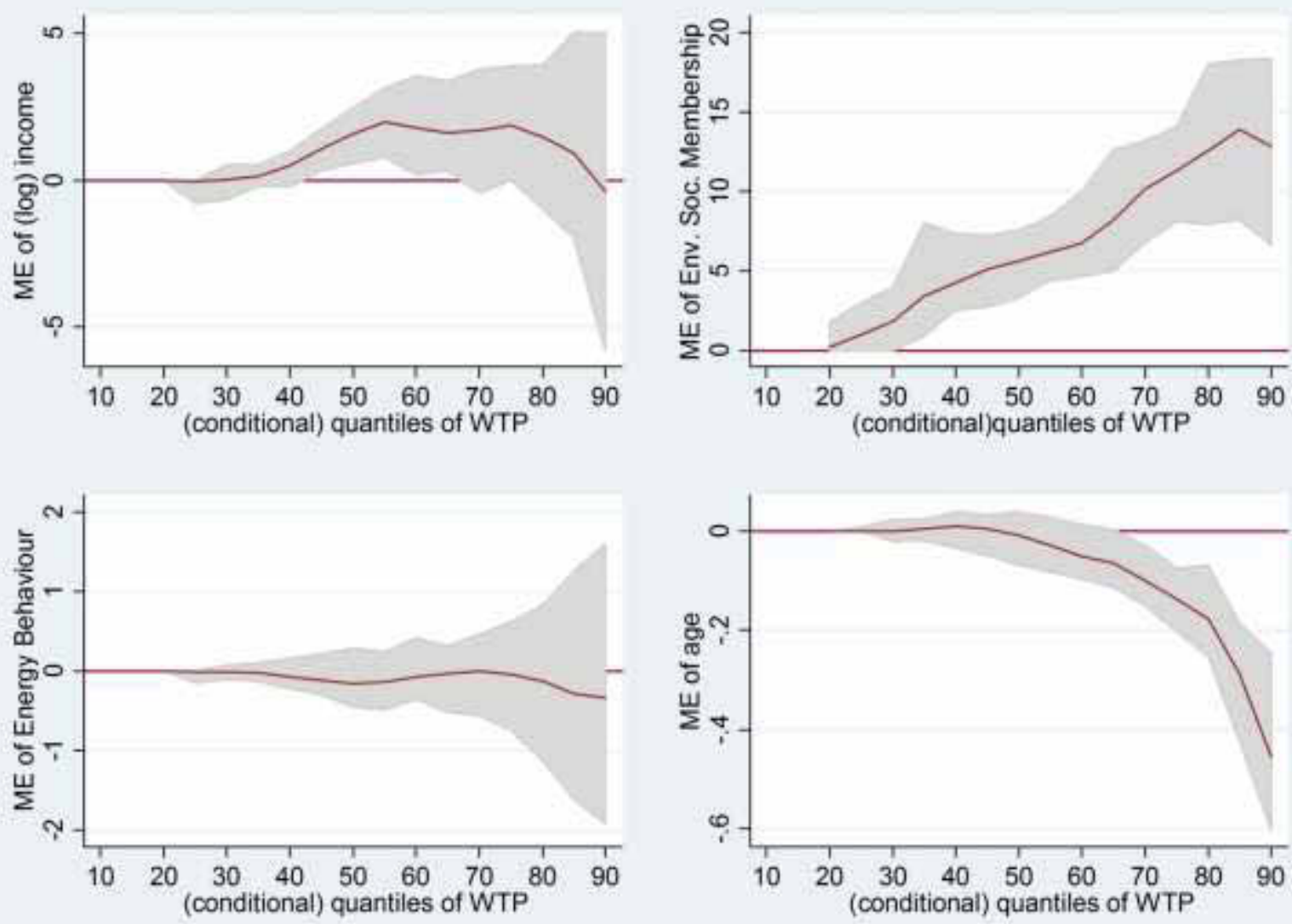

Note: Average marginal effects and (bootstrap) confidence intervals, independently estimated over a range of quantiles (see text). These estimates are then connected by a curve0. Estimation at each quantile also included country-specific fixed effects and estimation procedure used accounted for probability weighting. The grey region is the confidence region while the red colored lines are the estimated coefficients; therefore, only regions which do not overlap the zero line are considered "statistically significant".

Membership in an environmental organisation is positively related to WTP and the impact of this indicator is seen to increase with (conditional) WTP. In other words, conditional on other factors, the (marginal) impact of membership is larger with a higher WTP, with a probable "flattening out" around the $80^{\text {th }}$ percentile. An energy behaviour index, another proxy for "responsible behaviour" is never significant, just as with the conditional mean models. While Gender (figure not reported) never exerts a significant impact on $\mathrm{WTP}^{20}$, education does exert a positive impact, one which appears to be increasing across quantiles, similar to the effect of both household size and membership.

The effect of age is negative; conditional on other factors, the model suggests that older individuals have a lower WTP. One possible reason for the discrepancy between the conditional mean and conditional quantile results is neglected heterogeneity in the conditional mean framework.

To summarize, our quantile regression framework suggest that reported household income is not a determinant for the level of WTP, while our proxy of disposable income is marginally positively related. Age is negatively related in a distinctly non-linear way; i.e. age exerts a larger negative impact on higher

\footnotetext{
${ }^{20}$ Figure not reported due to space limitations.
} 
levels of WTP than on lower. Membership in an environmental organization is a strongly positive determinant of WTP, whose impact is increasing across WTP quantiles (i.e. the effects of membership are more pronounced for those who have a higher WTP). Education is marginally positively related to WTP, with the same increasing impact.

If we use econometric methods that are, in some sense, based on averages (conditional mean censored regression models), we will miss the fact that individuals with high/low WTP display a quantitatively different behaviour as regards their attitudinal and inherent characteristics. In a sense, the Tobit-style models "average out" these differences. 


\section{ENERGY DEMAND AND ENERGY EFFICIENCY}

This section details our analysis of electricity expenditure and energy efficiency. The two areas are, of course, intimately related. Recall that we would like to shed light on questions involving distributional issues, how attitudes correlate with energy efficiency and who takes advantage of grants. To fix ideas, we begin by describing frameworks that help suggest appropriate econometric models. Two "paradoxes" will be of concern. One is the so-called Jevons paradox (or rebound effect), the other the "slow adoption" paradox (or "energy efficiency gap"). The first says that promoting energy efficiency can increase energy use $^{21}$, the second holds that households (typically) are "too slow" in adopting "clearly economically beneficial" energy efficient technologies ${ }^{22}$.

\section{$1 \quad$ Framework}

There are several ways to think about energy efficiency within an economic framework. Here we first consider the economy as a whole, and then we turn to the households' decision process in detail. We will mostly use the second approach for organizing thinking about the empirical work, given the nature of our data. A birds-eye view of the economy is, however, useful in thinking about energy economics, so we begin with this perspective.

A policy directed towards energy efficiency typically means a lowering of the real price of energy. The $19^{\text {th }}$ century British economist Stanley W. Jevons pointed out that such policies may actually increase energy use (hence the Jevons paradox). In the modern literature, the Jevons paradox is typically called the rebound effect and has been intensely studied.

Is the paradox true? The answer depends (in general terms), firstly, on where we draw the system boundary. For example, if we save money (on net) by using a more efficient car, how will the saved resources affect energy use? One possibility is that we use the money on a more energy-inefficient good, e.g. on an imported steak; consequently, it is important to be clear about the system boundary. What we save in one activity may be lost in another, more energy-consuming, activity. Consequently, a birds-eye view, or a general equilibrium perspective, is really useful in this context.

Second, even if we make the system boundary very tight and just look at the particular activity under scrutiny, a lower real price may well lead to increased energy consumption. Suppose that we give out energy efficient light bulbs for free in a certain neighbourhood (as was actually the case in an English experiment). This may well increase energy use in the neighbourhood, precisely because the real price of energy is lower. Households may put light bulbs in the garden or in the garage etc., increasing both energy consumption and their utility of light bulbs (the mechanism is the same as explained in footnote 19).

${ }^{21}$ An example from Norway on subsidizing energy-saving air heating pumps is one out of many examples. It was found that those who installed the pump actually increased energy consumption. It was now cheaper to have a more pleasant temperature in the garage and so on; the households adjusted to the lower real price of energy. Source: Bente Halvorsen, Statistical Bureau, Norway, Pers. Comm.

${ }^{22}$ There is also the idea that there are substantial investments in energy efficiency available at negative costs. Available evidence suggests that this is a rather too optimistic assessment. 
Third, it is possible that a country, in its early development follows an efficient path in which both energy and output increases. At some turning point, energy input is lower, but output still increases. Such a path might well be optimal, because the price paid for a worsened environment is deemed to be worth paying. The inverted $U$ relationship has been studied in several contexts and derives from the so-called Kuznets curve, a classic study on the relationship between income distribution and development. Recent research reported in Liddle (2012) supports, for most OECD-countries, such an inverted U for energy in the period $1960-2009^{23}$.

Because our empirical analysis will be based on household data, we now turn attention to a way of structuring the analysis with the use of a framework based on the household. Again, while there are several possibilities, we retain an economic framework for our analysis.

\subsection{Residential energy demand in an economic model of the consumer}

It has long been recognised in the economics literature, at least since the beginning of the $1960 \mathrm{~s},{ }^{24}$ that residential demand for energy is most usefully considered as a step process, in which household decisions are made in stages. The idea is basically the same as was just presented in the case of the WTP analysis. In a first step, the consumer decides whether or not to buy a durable that provides a certain service (air condition, cooking, heating, lighting and so forth). In a second step, the consumer considers characteristics of the durable (e.g. efficiency, fuel type and new or "old" technology). In the third step, conditional on having bought the durable good, the consumer finally decides about the frequency and intensity of use. Note that we may well include housing itself as one of the capital stocks, see (Quigley 1984).

The discrete/continuous type of decision highlighted the fact that there may be a significant difference between responses in the short and long-run. In the short-run, the stock of appliances etc. is given, while it is allowed to change in the long-run. Hence, the difference between how consumers respond to changes in policy in the short and long run can be substantial. Furthermore, this theory naturally suggests that energy demand is a derived demand. Households demand the services generated via the energy input; energy is not demanded in the same way as we demand milk, potatoes or any other good.

Empirical studies on the residential energy demand flourished in the 1970s, propelled by the energy price increases. However, it was not until the publication of (Dubin and McFadden 1984) and (Hanemann 1984) that a robust methodology for handling the discrete/continuous components of choice was developed. Since then, a substantial literature on residential energy demand has developed, and we refer to surveys in OECD (2011 and 2014) for additional literature overviews beyond the studies we review next. This includes the literature on split-incentives, a kind of principal-agent problem, that is particularly important when the investor is not the same as the user; a typical case is the landlord-tenant problem, see IEA/OECD (2007) for a detailed discussion of this problem in the case of energy efficiency ${ }^{25}$. We will return to it in the empirical analysis below.

\footnotetext{
${ }^{23}$ The relationship is between total primary energy supply (TPES) divided by GDP, and time. For a review of 200 years of data, see Gales et al. (2007), who, incidentally, argues that the inverted U shape is not strongly supported.

${ }^{24}$ See the review by Hartman (1979).

${ }^{25}$ To illustrate the problem, one can consider a hotel owner and a guest; the latter wants to have a comfortable room temperature etc., while the former wants to minimize energy cost. The use of keycards in hotels can be seen as a way to handle the incentive problems; the keycard cuts out the lights (and possibly more) when the guest leaves the room.
} 


\section{$2 \quad$ Literature review}

The literature on residential energy demand, if expanded, as here, to include items such as energy efficiency and energy saving, is very large. There are several reviews, with different emphasis, available. OECD (2014) reviews the economics literature, with an emphasis on econometric studies, while a recent overview by Gillingham, Newell, and Palmer (2009) has more detail on economic analyses of decisions related to energy efficiency. Borenstein (2012) also has an economics perspective, but targets renewable electricity. The review in Wilson and Dowlatabadi (2007) covers several areas, including conventional and behavioural economics, technology adoption theory and attitude-based decision making, social and environmental psychology, and sociology. Abrahamse et al. (2005) presents studies with and social and environmental psychology view, in their review of 38 studies that studies "interventions" directed at reducing household energy consumption. Most of these studies look at "soft" policy measures and we highlight two general findings. First, frequent feedbacks as well as various "rewards" have been found to affect behaviour, albeit the effect being rather short lived ${ }^{26}$. Overall, information does improve knowledge but does not necessarily change behaviour in a significant manner.

If we combine the review in OECD (2011) with the additional studies covered here, one take-home message is that pointed, perhaps role-model based, information is much more likely to be effective compared to general information. In particular, contextual information might be most effective, as we will see below when we come to the literature on "nudges". Martinsson, Lundquist, and Sundström (2011) specifically looks at energy saving and environmental attitudes, but contains a concise review of the literature from a political science (roughly) angle. They review background factors such as age, attitudes and so; a detailed discussion of their paper is contained in OECD (2014). A similarly concise, yet farreaching review of insights from "behavioural science", is Amir et al. (2005), that we will return to below. Finally, Stern (2000) reviews theories of "environmentally significant behaviour" from a psychology point of view ${ }^{27}$.

In summing up insights from these literatures ${ }^{28}$, while we need to simplify considerably, the overall picture that emerges is the following. The standard economics literature maintains the importance of price and income as primary drivers ${ }^{29}$. Behavioural economics comes out as more positive towards alternative "nudges", as we will explain shortly ${ }^{30}$. Other social sciences, especially psychology, stress the importance of non-price policy instruments. The "slow adaption" paradox is mentioned in all these literatures; there are thus a multitude of different possible explanations, in turn because there are different theories of household behaviour ${ }^{31}$. If there is a common theme across literatures it might be heterogeneity; two observationally equivalent households may consume very different amounts of energy inputs. In turn, this means that averages can be misleading. Economists, such as Reiss and White (2008) have picked up on this theme (as we have in this paper's empirical analysis), and developed models that deal directly with the

\footnotetext{
${ }^{26}$ See also Seligman and Darley (1977) and Fischer (2008).

${ }^{27}$ Lutzenheiser (1993) has an extensive review of pertinent parts of sociology and similar subjects. It is somewhat dated, but still very useful in providing an in-depth review of the issues involved.

${ }^{28}$ We have deliberately left out the substantial amount of work that has been carried out from an engineering perspective, basically because the project focuses on household behavior.

${ }^{29}$ A stark example of this is Andersson (1997) who analyzes a large set of variables describing households and their electricity consumption, concluding that the only variables that are able to explain variations in energy demand are economic.

${ }^{30}$ Gsottbauer and Bergh (2010) summarizes the literature on behavioral economics from an environmental economics point of view and draw climate policy conclusions that deviate from the standard economics paradigms.

${ }^{31}$ A relatively simple framework in which to understand the paradox is provided by Allcott and Greenstone (2012).
} 
heterogeneity; additional examples will be discussed below. We turn now to a brief review of certain papers in the literature, using the three steps outlined above loosely as an organizing frame.

The first step is then the acquisition of a capital good that uses energy as an input to provide a service. From an economic point of view, this is a straightforward exercise in investment analysis. The consumer compares the present value of the investment with a set of alternatives (usually "not investing"). Provided that markets are competitive, including the capital market (a crucial assumption), whatever choice the consumer makes is (Pareto-) optimal. This assumes, inter alia, that the consumer is rational (in the economists sense of rationality), a particularly contested assumption in this literature. Let us briefly look at some of the debates.

\subsection{Deviations from rationality}

Economists and other social scientists/engineers often part company when it comes to the assumption of consumer rationality. Even so, an "in-house" critical line of thought that has become popular is typically explored in "behavioural economics" ${ }^{32}$. More generally, psychologists and sociologists have long critiqued the basic assumptions of the neoclassical model; in particular, consumer's ability to make rational long-run decisions is questioned. Explanations of "irrational choices" favoured by leading researchers from behavioural economics, psychology and sociology (Amir et al. 2005) include: the importance of choice architecture, status quo bias, the asymmetry of gains and losses according to prospect theory, and other deviations from the neoclassical model. These items are explained in detail in the compact survey of behavioural sciences by Amir et al. (2005).

Stern (1992) presents a particularly pointed critique of the rationality assumption from a psychology perspective. He maintains that "energy policymakers" tend to overlook social contexts within which energy savings decisions are made ${ }^{33}$. This point has a very interesting connection to recent research by economists, such as Allcott (2011). ${ }^{34}$ In his study of an extensive information program in the US, he finds that informing consumers about their neighbour's energy consumption patterns reduces energy consumption by about $2 \%$; more on this below. This type of research is an amalgamation of economic and psychology research and sometimes described as displaying the power of descriptive norms. For example, in this view, consumer will behave differently, if told that "most hotel guests re-use their towel" compared to "please re-use your towel so that we all conserve energy".

While a relatively novel research field in our context, the power of social norms has been studied for a long time in social psychology. Let us consider two examples from a growing literature. Nolan et al. (2008) presents an experiment with 810 respondents from California on energy conservation. They find that descriptive normative beliefs were better predictors of (changing) behavior, even though respondents rated such information least important. The authors claim that "results show that normative messages can be a powerful lever of persuasion but that their influence is under detected". The second example, mentioned above, is the so-called OPOWER program in the US. It allows a "live" test of these ideas, in particular testing information about peer behavior as a "nudge". The OPOWER program has its own

\footnotetext{
${ }^{32}$ Bernheim and Rangel (2009) is an example of recent work in economics where the standard rationality model is extended to include various "non-standard" behaviors. A recent paper by Shogren (2012) prepared for the OECD provides a critical review of the literature.

${ }^{33}$ To be precise, P.C. Stern (1992) states that "the underlying behavioral assumption is that technologies that will, over their useful life, save their owner-occupiers and operators money will be adopted once the owneroccupiers become aware of the benefits. Psychologists easily recognize that this assumption is far too simplistic." (p. 1224)

${ }^{34}$ See Brown et al. (2013) for an analysis of the importance of the status quo bias with respect to default temperature settings in energy consumption patterns.
} 
website (opower.com), "a customer engagement platform for the industry"; utilities can sign-up and household obtains detailed information its own and its neighbors energy use. According to the website, the company has 70 utilities among its customers and delivers home energy reports to 4 million customers.

The efficiency of peer comparisons, using data from OPOWER, has been tested by Allcott (2011) and Ayres, Raseman, and Shih (2012). Both find that that such "nudges" can be used to lower energy consumption in a cost-effective manner. Allcott (2009) claims that such programmes can "significantly affect consumer behavior" and its cost "compares favorably to price-based approaches of traditional energy-efficiency programs". It remains to be seen if these effects will be stable over time and if the net effect will be positive (those who consume less than the norm might increase their consumption when realizing this).

The research on the OPOWER program supports our recurrent heterogeneity theme, albeit in a different manner. According to Alcott (2009), it is possible to target descriptive norms programs such that only the responsive households are approached. In general, policy targeting is not unusual. There are many examples of fine-grained energy policies targeting the residential sector, e.g. so-called weatherization programs targeting a particular set of low-income households. Such targeting does require substantial amount of detailed information about consumers and appropriate econometric models, such as the quantile regression approach used here.

And finally, Kempton and Montgomery (1982) argued that households use cognitively efficient but economically inefficient approaches to energy consumption. Using rules of thumb, households make nonoptimal economic choices and "Folk calculations", such as how much energy lighting consumes, generally leads to differences between consumers and experts regarding energy efficient investments. This, then, is possibly another explanation of the slow adoption paradox. More on this below in a discussion of market failures, perhaps the most often motivation used to explain allegedly inefficient consumer choice in the energy market.

\subsection{Market failures}

We proceed by assuming that the consumer is rational in the economic sense and maintain loosely our connection to the adaption/investment decision. Can we still explain observed behavior via received economic theory? A popular line of research involves, as noted, market failures as main explanatory factors. Unfortunately, the concept of a "market failure" is not necessarily used in a homogenous manner in the literature. Linares and Labandeira (2010) lists $^{35}$ nine different examples used in the literature and space only allows brief comments on these. First, low energy prices are not market failures per se, but certainly impacts the consumer decisions ${ }^{36}$. If the "low" prices are due to fuel subsidies, the subsidies should be removed from an efficiency perspective; the market fails to generate the right amount of fuel use in that case. Hidden costs are costs that are not always included in analysis of consumer decisions. For example, there is a cost in finding a more efficient technology, let alone finding the optimal technology and installing it. Replacing a current direct electricity heating system with a system based on ground heating

\footnotetext{
${ }^{35}$ For similar lists, see e.g. Sovacool (2009), table 1. He also includes, in a list of what he calls "impediments", obstacles to renewable energy developments (in the USA).

${ }^{36}$ Sutherland (1991) discusses a case when pricing is based on average rather than marginal cost. This appears to be less of a problem today, at least in cases where the market is deregulated. At any rate, the prices are artificially low and entice little interest in energy conservation investments.
} 
pumps is a significant undertaking for most home-owner-occupiers ${ }^{37}$. If all hidden costs are included, the paradox might disappear. At any rate, hidden costs are not a market failure.

In the literature, consumers' reluctance to invest in energy saving appliances is often explained via informational failures. Lack of information may, on the other hand, be a market failure, depending on the precise nature of the information shortage. A consumer using, say, dishwasher brand $\mathrm{A}$ is not aware that a dishwasher B is available, even though it would provide the same services at a lower energy cost. This is not obviously a market failure, even though labelling would be one way of attacking such informational shortages. The Swedish remit on energy efficiency (SOU 2008) makes an overall assessment, based on various studies, that appliance labelling in the period 1995-2005 reduced energy (final) demand in Sweden by 0.3 Twh.

As explained by Jaffe and Stavins (1994), information failures also exist on the supply side; a builder might not be able to recover energy efficiency investments if he is unable to convince potential buyers about the actual efficiency of the house. In the empirical analysis we look at the difference between those who own their own house and tenants. ${ }^{38}$

Yet another reason why the consumer is not switching to an "obviously cheaper" technology, even if he is rational in the economic sense, could be capital market imperfections. Hence, if the consumer can make an investment with a return higher than observed in the market, why does he not use the capital market (borrow, if need be) and make the investment? One reason could be an imperfection in the market for consumer credit; there is, in fact, a whole typology of such imperfections, but the bottom line is that the consumer is unable to borrow at a rate both the bank and the consumer would find to their advantage. The gap is typically due to asymmetric information, a type of informational issue that is a market failure.

Alternatively, the consumer is using a "too high" discount rate and does not make the investment even though the present value (at the market rate of interest) is positive. There is quite a significant literature on this issue, beginning with Hausman (1979); (implicit) discount rates have been estimated in range 25-100\% according to the survey in Gillingham, Newell, and Palmer $(2009)^{39}$. This is well above market rates typically found. Empirical evidence display an almost breath taking variation, see e.g. table 1 in Frederick, Loewenstein, and O'Donoghue (2002); they cover many areas, including energy ${ }^{40}$.

Economists, psychologists and others have offered a catalogue of explanations for the high (implicit) discount rates found (in many areas) and we refer to the extensive review by Frederick, Loewenstein and O'Donoghue $(2002)^{41}$ for a useful discussion. In the case of energy investments, borrowing constraints (a market failure) have been offered as one explanation.

${ }^{37}$ Typically, there is quite a process in deciding which of several technologies best fit the actual house, drilling permits may be needed, negotiation with neighbors might be needed and so on and so forth.

${ }^{38}$ A number of issues arise when the agent does not pay the marginal cost of his/her decision, unmetered energy use in a rented dwelling is a typical example. More on this principal agent type of problem in the empirical section.

${ }^{39}$ Frederick, Loewenstein, and O'Donoghue (2002) report an even larger variation in their survey.

${ }^{40}$ Other areas e.g. include wage-risk trade-off (taking on a high paying job today, while risking a shorter life) and macroeconomic studies of life-cycle saving behavior.

${ }^{41}$ Frederick, Loewenstein, and O'Donoghue (2002, p. 386) point out that the high implicit discount rates observed in appliance studies, could be due to "..the inability to control for some important factors". These factors includes those we have already discussed, i.e. lack of information, belief that cost saving promise is oversold, difficulty translating information into economically efficient actions and hidden costs. 
There are other explanations of the paradox involving information in the future and expectations, e.g. the investing household might believe that the adoption costs fall in the future (Jaffe and Stavins 1994). There is no "paradox" if households are just waiting to get a better deal. Option value is a closely related idea, that could explain some of the tardiness observed without the need to change the rationality paradigm; it can be viewed as an extension of the net present value rule see (Hassett and Metcalf 1993). Baker (2012) extends the model to include many appliances. If a household makes the investment, it has killed the option of waiting for new information about prices; this option has no particular value in the standard investment theory under uncertainty.

In short, whether or not incomplete knowledge about existing energy investment opportunities are a market failure can be debated at length. We will not enter this debate here. One can still make a case for government information campaigns, if knowledge about future prices are unevenly distributed in the population and best known within some government agency (see Mäler 1977).

\subsection{Selected econometric studies}

Dubin-McFadden's (1984) and Hanemann's (1984) models explain why it is difficult to measure the price elasticity of electricity demand for an appliance in a household. A large family presumably expects to utilize a washing machine more than a single-person household and therefore is more likely to buy the more energy-efficient machine. Thus, the marginal cost is lower for the large family. To get around this problem, (Davis 2008) constructs an experiment in which a sample of households are given a highefficiency washer for free (48\% less energy and $41 \%$ less water per cycle relative to the standard). Thus, all participants face the same lower marginal cost. Washing increases $5.6 \%$ and the price elasticity of clothes washing is found to be a low -0.06. Thus, in this case, there is not much of a rebound effect - if we do not consider the "global effect" on energy consumption via the monetary savings implied - since clothes washing does not increase much. Davis (2008, p 531) concludes that "most households are better off buying a washer that meets the 2007 standard".

In a report to a Swedish remit on energy efficiency, Dargay (2008) uses econometric analysis to find that energy taxes installed in 1991 will, up to 2016, result in a saving of 9 TWh in car transport and residential heating. The effect is smaller in the residential sector, on net $3.45 \mathrm{TWh}$. She points out that Swedish households have switched from oil to biofuels (single-family houses) and district heating (flats) ${ }^{42}$.

Quigley and Rubinfeld (1989) look at residential energy consumption in dwellings, using hedonic framework. The price of a dwelling is considered a function of its attributes, including energy-related features such as the energy system (type of heating/cooling technology), insulation and so on. This allows the estimation of long-run effect of energy price changes, when consumers adjust their consumption pattern. Thus, the consumer can move to newer, and ostensibly more, energy-efficient dwelling with a different configuration of rooms and so on. The long-run price elasticity of energy demand is significantly larger, estimated at -0.7 , compared to -0.1 in the short run. Other econometric studies focusing the residential sector include Cameron (1985), Hassett and Metcalf (1993), Hassett and Metcalf (1995), Revelt and Train (1998) and Sardianou (2007). A more detailed review of econometric studies is in OECD (2014).

\subsection{Assorted other topics}

To wrap up this review, there are a number of assorted topics that we just briefly mention here and we do no better than refer the reader to Mundaca et al. (2010, table 3) for a review of studies on (i) energy

\footnotetext{
42 See Dargay (2008). The Government Commission (SOU 2008:25, p. 171) that solicited Dargay's report nevertheless argues that the bulk of energy efficiency improvements in those sectors will not come from (increased) energy taxes.
} 
efficiency and knowledge (ii) educational level and investments in energy efficiency (iii) links between investments in low-energy houses /appliances and perceived status. In all three cases, there is some evidence of positive correlations. Poortinga, Steg, and Vlek (2004) claims to be the first detailed study on the relationship between household energy use and values, using a sample of 2000 Dutch respondents (of which 455 returned a complete questionnaire). They find that home energy use is related to e.g. income, household size and level of education. However (p. 88), they conclude that "although the various (indirect and direct) measures of pro-environmental intent were significantly related to the value dimensions and especially to environmental concern, these variables could only explain a very small amount of variance in home and transport energy use." Compare Andersson (1997) quoted above, who found that economic variables were the only significant variables to understand appliance demand.

Let us now turn to our empirical analysis of some of these issues in the EPIC survey. Because of the different incentives tenants and owner-occupiers typically face regarding energy decisions in their residence, we will focus our analysis on these two groups.

Econometric analysis

We begin by looking at differences in adoption behaviour between tenants and landlords for a variety of energy efficient devices, including if there is a measurable difference between them in obtaining government grants (where available) for such devices. As noted, the landlord-tenant issue is well known in the energy economics literature. See Davis (2011) for a recent review of the literature. The crux of the issue are two variants of the principal-agent problem: when tenant pay the utility bills, landlords have little incentive to invest in (more costly) energy efficient devices/appliances ; analogously, when the costs of installing such devices is relatively high, tenants invest sub-optimally in many (more expensive) energy efficient devices.

Table 4 presents the summary statistics for the regression sample. A few features of the data are worth noting: it is evident that "owner-occupiers" as a group are sampled more than "tenants", and further, that while WTP is identical across them, incomes are substantially different. This is clearly an intriguing feature, given emphasis in the current literature on income as an explanatory factor for the magnitude of WTP, as explained in section 3. Substantial differences are also seen in the "size (in sq. meters)" of residences, and also in "electricity spending (in Euro)" across the group, in keeping with differences in income (i.e. owner-occupiers tend to inhabit larger houses) and the more marginal differences in household size. 
Table 4 Summary Statistics (mean) for Regression sample, disaggregated by Owner-Occupier and Tenant

\begin{tabular}{|c|c|c|c|c|c|}
\hline & Owner & Tenant & \#obs_Owner & \#obs_Tenant & p-values \\
\hline Wtp & 11.678 & 11.688 & 6200 & 3500 & 0.986 \\
\hline Income (Euro) & 42000 & 34000 & 6500 & 3800 & 0 \\
\hline \multicolumn{6}{|l|}{ Individual and Household Characteristics } \\
\hline Years of post-high school & 3.379 & 3.224 & 7700 & 4500 & 0.068 \\
\hline Household Size & 3.164 & 2.589 & 7700 & 4500 & 0 \\
\hline Home size & 117.927 & 79.398 & 7200 & 4000 & 0 \\
\hline Energy Behaviour index & 7.508 & 7.556 & 7700 & 4500 & 0.402 \\
\hline Electricity spending (euro) & 1048.703 & 741.952 & 3900 & 2100 & 0 \\
\hline Marital status ${ }^{*}(1=$ Married/living together $)$ & 0.675 & 0.493 & 7700 & 4500 & 0 \\
\hline Proportion Voting in Local Elections ${ }^{*}(1=y e s)$ & 0.788 & 0.634 & 7700 & 4500 & 0 \\
\hline $\begin{array}{l}\text { Proportion Voting in National Elections }{ }^{*}(1=y e s) \\
\text { Employment Category (Employed versus Not) } \\
\text { (1=Emploved) }\end{array}$ & $\begin{array}{l}0.843 \\
0.616\end{array}$ & $\begin{array}{l}0.721 \\
0.626\end{array}$ & $\begin{array}{l}7700 \\
7700\end{array}$ & $\begin{array}{r}4500 \\
4500\end{array}$ & $\begin{array}{c}0 \\
0.518\end{array}$ \\
\hline Env. Organisation Membership*(1=yes) & 0.079 & 0.076 & 7700 & 4500 & 0.644 \\
\hline $\begin{array}{l}\text { Age of } \mathrm{HH} \text { head } \\
\text { Prop. who consider energy costs when making } \\
\text { Home choice decisions }{ }^{*}(1=y e s)\end{array}$ & $\begin{array}{c}45.204 \\
0.29\end{array}$ & $\begin{array}{r}38.907 \\
0.243\end{array}$ & $\begin{array}{l}7700 \\
7000\end{array}$ & $\begin{array}{l}4500 \\
4100\end{array}$ & $\begin{array}{c}0 \\
0.001\end{array}$ \\
\hline \multicolumn{6}{|l|}{$\begin{array}{l}\text { Prop. Who use Energy Efficient } \\
\text { Devices/Technologies }\end{array}$} \\
\hline Energy Efficient Appliances & 0.642 & 0.51 & 6800 & 3300 & 0 \\
\hline Energy Efficient Bulbs & 0.766 & 0.65 & 7100 & 3900 & 0 \\
\hline Ground Source Heat Pumps & 0.029 & 0.02 & 6600 & 2500 & 0.021 \\
\hline Solar Panels & 0.074 & 0.041 & 6500 & 2500 & 0 \\
\hline Thermal Insulation & 0.369 & 0.161 & 5800 & 2300 & 0 \\
\hline Heat Thermostats & 0.34 & 0.207 & 6200 & 2500 & 0 \\
\hline Wind Turbines & 0.014 & 0.012 & 6600 & 2500 & 0.301 \\
\hline Energy Efficient Windows & 0.428 & 0.229 & 6100 & 2500 & 0 \\
\hline \multicolumn{6}{|l|}{ Prop. Who use Govt. Support for purchasing } \\
\hline Energy Efficient Appliances & 0.205 & 0.195 & 4100 & 1600 & 0.633 \\
\hline Energy Efficient Bulbs & 0.143 & 0.126 & 5600 & 2700 & 0.11 \\
\hline Ground Source Heat Pumps & 0.589 & 0.563 & 240 & 56 & 0.778 \\
\hline Solar Panels & 0.586 & 0.514 & 730 & 180 & 0.344 \\
\hline Thermal Insulation & 0.172 & 0.253 & 2100 & 430 & 0.012 \\
\hline Heat Thermostats & 0.146 & 0.177 & 2100 & 510 & 0.202 \\
\hline Wind Turbines & 0.542 & 0.641 & 100 & 36 & . \\
\hline Energy Efficient Windows & 0.22 & 0.228 & 2400 & 570 & 0.778 \\
\hline
\end{tabular}

Note: Means are based on the relevant sub-sample: sample sizes are shown in the table. "P-values" refer to the $p$-value of a twosided ( $\mathrm{t}-$ ) test for mean difference between the two samples (Owner and Tenant). Variables under "Individual characteristics" with an "*” represent indicator variables, whose "mean" values are simply proportion of the sample with a "1". The summary statistics appropriately take into account the complex survey nature of the data (including adjustments to test statistics and the mean itself). This implies, in particular, that the "means" reported above are not simply the "raw means" of the sample. 
Owner-occupiers as a group are also more likely to report "married or living together", compared to tenants, and are also substantially older. Both factors indicate that "owner-occupiers", as a group, tend to have a very different social profile, one not reflected in the "employment" category, since they are also much more likely to be pensioners (figures not reported). Note that tenants are just as likely as ownerowner-occupiers to be members of an environmental organization, and are just as "responsible" in their attitude towards energy saving (have very similar "energy saving behaviour" scores). In a nutshell, tenants are younger, less well off, less likely to be married and/or having children and spend less on electricity. On the other hand, there is no difference between owner-occupiers and tenants regarding WTP for green energy and being a member of an environmental organization.

Turning now to energy behaviour in these two groups, we begin with the propensity for buying energy efficient devices. Except for wind turbines ${ }^{43}$, there is clearly a substantially greater tendency among owneroccupiers to own energy-efficient devices ${ }^{44}$.

Next we examine the issue of obtaining grants for each of the energy efficient devices considered ${ }^{45}$. Since responding to that question is contingent on actually having bought the device in question, sample sizes vary substantially by device, and for certain devices, samples are unsatisfactorily small. Except for "thermal insulation" 46 , conditional on purchasing an energy efficient device, tenants are as likely as owneroccupiers to apply for a government grant. The existence of a grant raises many interesting questions, including of the issue of whether or not the existence of a grant makes it more likely that certain individuals are likely to invest in purchase of energy efficient device. This is investigated below.

Overall, there are quite clearly substantial differences in mean outcomes between owner-occupiers and tenants, across many dimensions, and such differences provide a basis, and impetus, for further investigation. Yet, given the independent nature of such comparisons (e.g. income differences do not control for differing education levels, nor for age) it is not clear if such differences reflect simply an effect of the underlying owner-tenant dichotomy or are being driven by common, unobserved factors (or combinations of observed factors). In order to address this issue, we turn next to a regression framework.

\subsection{Regression analysis: grants for energy efficient devices}

We address the issue of choice of an energy-efficient device as being independent of the decision to (attempt to) obtain a grant. By design, a grant is an instrument meant to increase probability of adoption of an existing device; yet, we do not have information on which individual, in which country, had eligibility to apply for a grant for which specific device. In the absence of such information, the resulting model results are difficult to interpret ${ }^{47}$. Further, the data on hand pertain to whether a given individual owns (and

${ }^{43}$ In the case of Wind Turbines, there is a clear issue with sample size, with only 158 individuals (115 Owneroccupiers and 42 Tenants) which, when combined with population weights, yield the results above, that both groups are equally likely to own one.

${ }^{44}$ Unlike in Davis (2011) there is no question indicating which of the many appliances that individuals report owning are actually the "Top Labeled Energy efficient" ones, and therefore, it is not possible to answer the more specific question of which type of individuals purchase which type of appliances.

${ }^{45}$ So far as we are aware of, there are few studies which explicitly consider the issue of government grants in an Owner-Tenant context.

${ }^{46}$ For which sample sizes are too small to permit computation of a test statistic with weighting.

${ }^{47}$ A further complication is that, in the setting of a complex survey, a model in which a decision to purchase is made jointly with the decision to obtain (apply for) a government grant is highly complex and computationally challenging. We are currently working on developing such a model and hope to report results in a subsequent iteration. 
therefore, purchased in the preceding 5 years) any energy efficient device. We adopt a model related to the probability of purchase of an energy efficient device. Formally, we use a "probit" model for each particular decision being modelled.

Thus, for each decision (purchase of a device and obtaining a grant for the device), the model estimated is of the form:

$$
P\left(Y_{i}=1\right)=\Phi\left(X_{i} \beta+\alpha I\{\text { Owner }\}\right)
$$

where $\mathbf{X}_{\mathbf{i}}$ is a vector of covariates (see Table for specifics) and $\mathbf{I}\{\boldsymbol{O} \boldsymbol{w n e r}\}$ is an indicator (dummy) variable for a home owner and $\Phi($.$) represents the distribution function of a standard normal variate.$ Interest in our case centres on the impact on this probability of being an owner-occupier which, in a linear model, would be the coefficient $\alpha$; in our case, however, since the function $\Phi($.$) is non-linear (in parameter$ $\alpha$ ), we report instead the marginal effects i.e. the discrete difference in $P\left(Y_{i}=1\right)$ between owner-occupiers and tenants ${ }^{48}$. Given that the value of the "marginal effects" is different for each observation, an "average marginal effect" is reported; i.e. the marginal effect is computed at each observation and a grand average of such marginal effects is reported. ${ }^{49}$

A positive marginal effect implies that owner-occupiers are more likely to own the device in question, relative to tenants. ${ }^{50}$ Sample sizes vary (not reported) from question to question due to the number of nonresponses, which are much higher in case of "devices" with high fixed costs or physical constraints on installation (such as wind turbines and heat pumps, for instance). The two types of decisions (purchase decision and obtaining a grant decision) each have three columns, with the only difference between the columns being the type of control variables employed, ranging from only country fixed-effects to, in addition, income and household characteristics ${ }^{51}$. The $4^{\text {th }}$ column in each decision space is the p-value from a t-test for model significance, which is passed by all models in the "purchase" decision but not by many in the "grant" decision (see discussion below).

The marginal effects actually correspond to changes in proportion, and we shall interpret them as percentage changes without loss of generality. For instance, in Row I of the "Device Purchase Decision", the coefficient of 0.0673 in the Column III is interpreted as follows: an owner-occupier is $6.7 \%$ more likely

${ }^{48}$ It is important to note that this "marginal effect" we report is typically of the same sign as the coefficient $\alpha$; the magnitude however can be substantially different.

49 It is important to note that, with many indicator variables - as in the case here - this ensures that the marginal effects correspond to an "average individual", not to any particular category (for instance, male employed and Owner). It is also possible to compute category-specific marginal effects which, for the sake of brevity, we do not report.

${ }^{50}$ An ancillary benefit of the probit (or any categorical regression) framework is that information from households who do not own the device in question can be beneficially used, unlike in the say Linear Probability Model (LPM), wherein the " 0 's" must necessarily be omitted from the regression framework. This is an important reason for the choice of a relatively difficult to interpret categorical regression framework, in comparison to the simpler LPM.

${ }^{51}$ A full list of the characteristics is as follows: household characteristics (home type-multi-unit versus single unit--, home size, energy consideration in home decision, number of members in household), socio-economic characteristics (income-linear splines-years of post-school education) and individual characteristics (age, sex, marital status and employment status). See relevant tables for specifics of controls. 
(than a tenant, the omitted category) to own an energy efficient appliance, controlling for important observed characteristics (controls indicated in the last Row, for all columns) ${ }^{52}$.

Consider the decision to purchase an energy efficient ("Top Energy Rated") appliance. The coefficient in Row I, Column I indicates that owner-occupiers are $10 \%$ more likely than tenants to have purchased an energy-efficient appliance, controlling only for country-level fixed effects. When household income is added as a control, the coefficient is reduced to $8.5 \%$ consistent with the data indicating that owner-occupiers are likely to both have higher income and an energy efficient appliance. When additional household and socio-economic controls are added, for example size of household and area of the house, the coefficient is further reduced, to $6.8 \%$. This is consistent with the descriptive statistics present in the summary table, Table 1; Owner-occupiers are likely to have more individuals living in the household, are likely to be older and to have larger homes, on average ${ }^{53}$.

While a finding that owner-occupiers are far likelier than tenants to purchase energy-efficient appliances accords with prior intuition (and with the relative cost of moving such appliances), the finding of a 5\% increase in probability of purchase of energy efficient bulbs for owner-occupiers is far more surprising, given the relative portability of such bulbs (the previous pattern of decreasing coefficient with additional controls holds true here). It is unclear if the investment horizon, relative to income, is such that the decision to purchase yields a lower net present value to tenants ${ }^{54}$.

For relatively fixed (or costlier-to-move) investment such as heat pumps, solar panels and heat thermostats, the increased likelihood of investment by owner-occupiers (by $1.3,4$, and $6.7 \%$, respectively) is unsurprising; what is surprising is the relatively small differences between owner-occupiers and tenants for heat pumps, compared to solar panels and heat thermostats. It is however, for fixed and almost immobile investments such as energy-efficient windows and thermal insulation that substantial differences are apparent (15\% and 19\% respectively). This is consistent with a high fixed cost being recovered over a relatively long time horizon, and thus for which there is danger of asset stranding ${ }^{55}$.

It is interesting to note that the magnitude of these coefficients are not far from the raw differences in proportion of owner-occupiers and tenants who make such investments, which is approximately $20 \%$ for both of these choices. In comparison, the home ownership effect has an impact on other investments which are typically smaller than the raw difference in device ownership percentages, indicating that a substantial part of the difference is attributable to differences in observed characteristics of the two groups.

In summary, we note the existence of an "owner-occupier" effect in the purchase (owning) of energy efficient devices across a range of devices, with a substantially larger magnitude of the effect for relatively immobile investments (such as windows and thermal insulation). We note, in passing, that all of the

${ }^{52} \mathrm{We}$ do not include unit electricity prices, the reason being that data on per-unit prices are unavailable at the individual or even sub-national level. Using national-level data, on the other hand, is identical to using country fixed effects (barring a shift in the magnitude).Given that it is not possible to estimate the priceeffect, the country-level fixed effects are sufficient to control for them.

${ }^{53}$ Of course, if an implication of these factors is a lower per capita (or disposable) income, or lower electricity prices (were they available), then the coefficient could increase in size. It is thus not necessary that the coefficients monotonically decrease as additional controls are added. They do so here, and accord with the intuitive reason for including such covariates. An instance of an increase in the coefficient is that on "Solar Panels".

${ }^{54}$ Given the differences between Owner-occupiers and Tenants, it is possible that Tenants and Owner-occupiers differ in factors such as access to credit (implicit interest rate) or individual discount rates, factors which cannot be tested or accounted for here.

${ }^{55}$ As well as with differential discounting and interest rates faced. 
models have good explanatory power (p-values of zero against a test that all covariates excluding the country-fixed effects have coefficients of zero). These results are very similar to what was obtained for the case of the US, reported in Davis (2011). Note that, unlike in that study, we do not attempt explicitly to compute the possible policy implications, in terms of changes in energy use, in a counter-factual scenario wherein the behaviour of both owner-occupier and tenant are similar, since we do not have unit electricity prices and attributing average prices can simply reflect cross-country differences, instead of differences in home ownership.

We turn next to understanding if there is any significant difference between owner-occupier and tenant in a tendency to obtain government subsidies for the energy efficient device in question. Note that these differences may also reflect differences in the propensity to apply for support: we are not able to distinguish between individuals who are able to apply for a subsidy for a given appliance and those who are not able to do so for a variety of reasons, including the non-existence of such a programme.

Either due to the purely random nature of the decision or due to an insufficient sample size (except in the case of appliances and bulbs, the sample size is rather small for analysing the government grant decision, as seen in the table), model fit is unsatisfactory in the case of energy efficient appliances and heat pumps. In addition, the coefficients on owner-occupier in all but two cases, while positive, are not statistically significant. We conjecture that there are two possible reasons for this: one, conditional on making a decision to purchase these devices, owner-occupiers and tenants have very similar propensity to obtain grants and two, the possibility of obtaining a grant has already been factored in a purchase decision. Distinguishing between these two would be an important avenue for further research.

While it is not possible to test formally these competing hypotheses, there is little difference in government grant outcomes between the two groups except in the case of thermal insulation and wind turbines. It is exactly these two decisions, however, which also report a significant coefficient indicating that, even unconditionally, the results above are likely to hold i.e. even after accounting for other important covariates which influence the decision, owner-occupiers differ from tenants in a substantial manner.

Curiously, owner-occupiers tend to be less likely to have obtained government grants for these two devices. Since other characteristics which affect the decision, such as income and age-related ones, have already been controlled for, one reason for the observed differences could be due to the substantial fixed costs involved in these devices. Because owner-occupiers are significantly more likely to own these devices it is plausible that the tenants are more likely to exert a greater effort to obtain a grant or subsidy, to reduce the capital expenditure involved.

However, in the absence of both data on either capital expenditure on each device, and with a very small sample size for the actual ownership of such devices, it is difficult to make more precise the actual cause of these differences. In sum, differences between owner-occupiers and tenants in obtaining government grants are difficult to identify, and in cases where they have been identified for two capital intensive devices, owner-occupiers are less likely to obtain a grant than are tenants. 
Table 5 Effect of home owning on different appliance/technology choices and on govt. grant applications for purchase of these appliances/technologies

\begin{tabular}{|c|c|c|c|c|c|c|c|c|}
\hline & \multicolumn{3}{|c|}{ Device Purchase Decision } & p-value & \multicolumn{3}{|c|}{ Govt. Grant Decision } & \multirow{2}{*}{$\begin{array}{r}\text { p-value } \\
0.169\end{array}$} \\
\hline $\begin{array}{l}\text { Energy Efficient } \\
\text { Appliances }\end{array}$ & $\begin{array}{c}0.109^{* * *} \\
(6.50)\end{array}$ & $\begin{array}{c}0.0845^{\star * *} \\
(4.67)\end{array}$ & $\begin{array}{c}0.0673^{\star \star \star} \\
(3.36)\end{array}$ & 0.000 & $\begin{array}{c}0.00975 \\
(0.49)\end{array}$ & $\begin{array}{c}-0.00409 \\
(-0.19)\end{array}$ & $\begin{array}{c}0.00630 \\
(0.26)\end{array}$ & \\
\hline $\begin{array}{l}\text { Energy Efficient } \\
\text { Bulbs }\end{array}$ & $\begin{array}{c}0.0827^{* * *} \\
(5.89)\end{array}$ & $\begin{array}{c}0.0678^{* * *} \\
(4.34)\end{array}$ & $\begin{array}{c}0.0516^{\star \star \star} \\
(2.94)\end{array}$ & 0.000 & $\begin{array}{c}0.00105 \\
(0.10)\end{array}$ & $\begin{array}{c}0.0123 \\
(0.96)\end{array}$ & $\begin{array}{c}0.00453 \\
(0.33)\end{array}$ & 0.000 \\
\hline $\begin{array}{l}\text { Ground Source } \\
\text { Heat Pumps }\end{array}$ & $\begin{array}{c}0.00814 \\
(1.78)\end{array}$ & $\begin{array}{c}0.00775 \\
(1.58)\end{array}$ & $\begin{array}{c}0.0132^{\star \star} \\
(2.32)\end{array}$ & 0.000 & $\begin{array}{l}-0.0118 \\
(-0.14)\end{array}$ & $\begin{array}{c}0.0690 \\
(0.75)\end{array}$ & $\begin{array}{l}0.144 \\
(1.56)\end{array}$ & 0.332 \\
\hline Solar Panels & $\begin{array}{c}0.0334^{* * *} \\
(3.89)\end{array}$ & $\begin{array}{c}0.0371^{* \star *} \\
(4.26)\end{array}$ & $\begin{array}{c}0.0415^{\star \star \star} \\
(4.12)\end{array}$ & 0.000 & $\begin{array}{c}0.0325 \\
(0.45)\end{array}$ & $\begin{array}{c}0.0540 \\
(0.82)\end{array}$ & $\begin{array}{l}0.103 \\
(1.39)\end{array}$ & 0.093 \\
\hline Thermal Insulation & $\begin{array}{l}0.217^{* * *} \\
(12.44)\end{array}$ & $\begin{array}{l}0.206^{\star * *} \\
(11.12)\end{array}$ & $\begin{array}{c}0.197^{\star \star \star} \\
(9.96)\end{array}$ & 0.000 & $\begin{array}{c}-0.0722^{\star *} \\
(-2.70)\end{array}$ & $\begin{array}{l}-0.0757^{*} \\
(-2.52)\end{array}$ & $\begin{array}{c}-0.0594^{\star} \\
(-1.81)\end{array}$ & 0.002 \\
\hline Heat ThermoStats & $\begin{array}{c}0.0886^{* * *} \\
(6.37)\end{array}$ & $\begin{array}{c}0.0636^{\star \star \star} \\
(4.19)\end{array}$ & $\begin{array}{c}0.0608^{\star \star \star} \\
(3.57)\end{array}$ & 0.000 & $\begin{array}{l}-0.0270 \\
(-1.21)\end{array}$ & $\begin{array}{l}-0.0111 \\
(-0.43)\end{array}$ & $\begin{array}{c}-0.00443 \\
(-0.15)\end{array}$ & 0.012 \\
\hline Wind Turbines & $\begin{array}{c}0.000494 \\
(0.17)\end{array}$ & $\begin{array}{c}0.00190 \\
(0.56)\end{array}$ & $\begin{array}{c}0.00657 \\
(1.55)\end{array}$ & 0.000 & $\begin{array}{l}-0.0931 \\
(-0.92)\end{array}$ & $\begin{array}{l}-0.0918 \\
(-0.83)\end{array}$ & $\begin{array}{l}-0.166^{\star} \\
(-1.66)\end{array}$ & 0.000 \\
\hline $\begin{array}{l}\text { Energy Efficient } \\
\text { Windows }\end{array}$ & $\begin{array}{l}0.172^{\star * \star} \\
(10.20)\end{array}$ & $\begin{array}{c}0.156^{\star \star \star} \\
(8.76)\end{array}$ & $\begin{array}{c}0.151^{\star \star \star} \\
(7.84)\end{array}$ & 0.000 & $\begin{array}{c}-0.000928 \\
(-0.03)\end{array}$ & $\begin{array}{l}-0.0184 \\
(-0.56)\end{array}$ & $\begin{array}{l}-0.0126 \\
(-0.37)\end{array}$ & 0.007 \\
\hline $\begin{array}{l}\text { Household } \\
\text { Income(Splines) }\end{array}$ & No & Yes & Yes & & No & Yes & Yes & \\
\hline $\begin{array}{l}\text { Other household } \\
\text { Characteristics }\end{array}$ & No & No & Yes & & No & No & Yes & \\
\hline
\end{tabular}

Average Marginal effects; $t$ statistics in parentheses

${ }^{* * *} \mathrm{p}<0.01{ }^{* *} \mathrm{p}<0.05{ }^{*} \mathrm{p}<0.1$

Notes: Reported in the table are Average Marginal Effects (AME's) on the indicator variable for "ownership", with t-statistics in parentheses. Each regression (a probit) has as dependent variable an indicator variable corresponding to the category on the row title and a set of dependent variables which vary as indicated in the different columns (the full list of dependent variables are provided in the text). There are two sets of results, corresponding to two types of questions: the first pertains to the decision to purchase (invest in) an energy efficient device, and the second, to using a government grant for such a purchase. Each question is modeled independently of the other. All regressions include country fixed effects and take into account the complex survey nature of the data. The columns called "p-values" refer to the $p$-value of the test for model significance i.e. the p-values from a joint test that all coefficients (except for country-fixed effects) are 0 . For reasons noted in the Appendix, we use a Wald approach to testing. 
Table 6 Determinants of Electricity demand

\begin{tabular}{|c|c|c|}
\hline & $\begin{array}{c}\text { With missing values } \\
\text { log(electricity spending) }\end{array}$ & $\begin{array}{c}\text { Imputation for missing values } \\
\text { log(electricity spending) }\end{array}$ \\
\hline \multirow[t]{2}{*}{ Members in household } & $0.124^{\star \star \star}$ & $0.112^{\star \star \star}$ \\
\hline & $(9.66)$ & $(9.86)$ \\
\hline \multirow[t]{2}{*}{ Log (Household income) } & $0.143^{* \star *}$ & $0.150^{\star \star \star}$ \\
\hline & $(4.27)$ & $(5.52)$ \\
\hline \multirow[t]{2}{*}{ Size of Primary Residence } & $0.000749^{*}$ & $0.00102^{\star \star \star}$ \\
\hline & $(1.89)$ & (3.49) \\
\hline \multirow[t]{2}{*}{ Home Type(1=Multi-dwelling) } & $-0.178^{\star *}$ & $-0.226^{\star * *}$ \\
\hline & $(-2.57)$ & $(-5.21)$ \\
\hline \multirow[t]{2}{*}{ Ene. consideration Home purchase $(1=$ Yes $)$} & -0.0241 & -0.00136 \\
\hline & $(-0.50)$ & $(-0.04)$ \\
\hline \multirow[t]{2}{*}{ Home Owner-occupier(1=Owner) } & $0.140^{\star * *}$ & $0.0784^{* *}$ \\
\hline & $(3.03)$ & (2.34) \\
\hline \multirow[t]{2}{*}{ Urban Area (1=Urban) } & $-0.147^{\star \star \star}$ & $-0.134^{\star * *}$ \\
\hline & $(-2.82)$ & $(-3.63)$ \\
\hline \multirow[t]{2}{*}{ Age of $\mathrm{HH}$ head } & $0.00318^{\star}$ & $0.00322^{* *}$ \\
\hline & $(1.76)$ & (2.50) \\
\hline \multirow[t]{2}{*}{ Gender(1=Male) } & 0.0546 & 0.0401 \\
\hline & $(1.32)$ & $(1.29)$ \\
\hline \multirow[t]{2}{*}{ Years of Post-Secondary Education } & 0.0115 & 0.00794 \\
\hline & $(1.23)$ & $(1.19)$ \\
\hline \multirow[t]{2}{*}{ Employment Status(1=Employed) } & -0.0466 & -0.0523 \\
\hline & $(-1.04)$ & $(-1.47)$ \\
\hline \multirow[t]{2}{*}{ Identify Energy Efficiency Label? } & -0.0223 & -0.0399 \\
\hline & $(-0.46)$ & $(-1.08)$ \\
\hline \multirow[t]{2}{*}{ Energy Efficient Appliances(1=Yes) } & $-0.350^{\star *}$ & $-0.419^{\star \star \star}$ \\
\hline & $(-2.34)$ & $(-3.03)$ \\
\hline \multirow[t]{2}{*}{ Member of Envt. Organisation } & $-0.0493^{*}$ & $-0.0391^{*}$ \\
\hline & $(-1.68)$ & $(-1.95)$ \\
\hline Observations & 4651 & 7365 \\
\hline F-stat & & 83.62 \\
\hline
\end{tabular}

$$
{ }^{*} p<0.1,{ }^{* *} p<0.05,{ }^{* * *} p<0.01
$$

Notes: Reported in the table are Average Marginal Effects (AME's), with t-statistics in parentheses, from a maximum likelihood regression, with dependent variable (log of) electricity consumption,. A treatment effects IV framework is adopted to deal with the endogeneity of the decision to purchase (own) a top-rated energy efficient device, one of the covariates (see text for details, including a full list of covariates). All regressions include country-fixed effects (coefficients not reported) and take into account the complex survey nature of the data (i.e. account for sampling weights and report appropriate standard errors). Column II reports results from the same regression as in I, but with missing values in the electricity spending variable imputed, via a multiple imputation methodology (see text). The standard errors reported also take into account the additional uncertainty induced by the imputation process. 


\subsection{Electricity consumption}

We turn next to evaluating the relationship between electricity consumption (in euro) and selected important determinants. Letting $Y_{i}$ and $P_{i}$ denote respectively the income and price faced by the ith consumer, and $Q_{i}, X_{i}$ a vector of his attitudinal and socio-economic characteristics, $A_{i}$ denoting a decision to purchase an energy efficient appliance and $E_{i}$ denoting his consumption of electricity (annual), interest centers on estimation of the following equation:

$$
E_{i}=\alpha+\beta p_{j}+\gamma Q_{i}+\delta X_{i}+\lambda Y_{i}+\kappa A_{i}+\varepsilon_{i}
$$

The following interpretation of the relevant coefficients is evident (assuming $E_{j}$ is the $\log$ of electricity consumption); $\beta$ and $\lambda$ are respectively the (own) price- and income-elasticity of electricity consumption, $\gamma$ and $\kappa$ are the shifts induced by attitudinal factors and appliance owning decisions (i.e. the potential difference between adopters and non-adopters), respectively.

The main issue raised by a naïve OLS estimation of the equation is that the coefficient on $A_{i}$ may be biased due to a possible endogeneity issue; individuals may choose an energy efficient appliance precisely because energy consumption is reduced as a result of the choice. It is important to notice that not just does this bias the coefficient on $A_{i}$; coefficients on potentially all variables are biased. In energy economics, typically, this bias is ameliorated by either explicitly making distributional assumptions regarding the form of dependence between the decision to choose an energy efficient appliance and the error term $\varepsilon_{i}$. An alternative approach is to treat the equation as simply a regression with an endogenous binary variable, and to use the very well-studied treatment effects approach. This is the approach we pursue here, and note that in the case of a binary alternative here (purchase versus not), both approaches are identical. ${ }^{56}$

At this stage, it is important to point out that while we purport to "model jointly" the appliance purchase and electricity usage decision, both decisions in our data set have a distinct time frame difference (i.e. are not contemporaneous, with appliance purchase typically leading by a few years the consumption measured here) and what consumers here are "purchasing" is not an appliance as such but a quality of the (to us, unknown) appliance viz. energy efficiency. Therefore, the usual interpretation, with joint estimation of the appliance purchase decision, of the coefficient on income as "long run" elasticity is somewhat inappropriate in our case. We will continue to interpret our results from a "short run" perspective. This is because the reason for addressing the potential endogeneity issue is to capture underlying preferences which influence electricity consumption, apart from such non-economic factors as attitudinal ones used here.

Three approaches are feasible in this framework, the possibly more robust IV (2SLS) approach, a "control function" approach and the maximum likelihood approach, which last we adopt (see Appendix for details). In this approach, the "endogenous" binary variable is modelled using a probit approach, and the two-related regressions are jointly estimated in a ML framework ${ }^{57}$. We perform two sets of regressions, the

${ }^{56}$ Simply dropping potentially endogenous variables from the model would result in 'omitted variable bias' with estimates on other coefficients - including those of primary interest such as income - being underestimated or over-estimated.

${ }^{57}$ As before, ours is a complicated set up in which no simple model selection procedure exists; standard LR tests are precluded due to the survey nature of our data, and in the case of the model at hand, a treatment effects regression, there is no over-identification test which is not based on the likelihood. On the other hand, even doing a two-step estimation (if feasible, which it is not in our case) would not necessarily yield very 
first with the raw data on electricity spending, and the second, with missing values imputed using a specific procedure, to which we turn next.

Missing data on electricity spending is a concern; roughly half the respondents (6164) did not provide any data. When combined with other variables in regression framework, each of which have a few missing variables, we are left with only around 4500 observations, reducing the statistical power of the regression (via increased variance). Primarily for this reason, although there are possibly added benefits in terms of robustness to certain kinds of biases (see Appendix), we use Multiple Imputation. This is a method in which "multiple data sets" are created by filling in the missing values; the analysis is performed on each of the individual datasets as if the datasets were independent and the results of the analysis are them combined together, taking into account the two sets of uncertainties: that "within" each dataset (due to the imputation process), and that "across" each imputation.

The results of such an imputation analysis are valid under broadly general conditions, which are quite likely satisfied in the survey (see Appendix for some details). With this approach, the sample size is larger but not very large, since many of the dependent variables had missing values too. The survey does not provide any source of per unit electricity prices faced by the consumer, and there is little publicly available data on sub-national variation in electricity prices. In the absence of such data, using only national-level prices possesses two drawbacks: being unrepresentative of actual prices faced, there are interpretational difficulties, and second, since they vary only across countries, they cannot be identified separately from the country-level fixed effects. For these reasons, we do not include country-level prices in our regression and cannot therefore estimate price elasticities.

This can potentially bias our results, an effect whose direction is difficult to sign a priori. On the other hand, Reiss \& White (2005) show, using a large house-hold level data set for California, that a large part of the price responsiveness is due to a rather small part of the sample (with a specific purpose/appliance); if such a result holds in our case, then the resulting bias might be rather small. Estimating these effects is an important task, which we leave for future rounds of the OECD survey.

We turn next to understanding the results of the regression. Given the substantial skewness in the distribution of electricity spending, we use log of electricity spending as the dependent variable in the regression. For similar reasons, we also use log of income. One convenient outcome of this aspect is the interpretation of the coefficient on income as elasticity ${ }^{58}$. On the other hand, it is much less clear how to interpret the coefficients on the binary variables included, since they are neither elasticities nor direct changes on levels.

informative information with the conventional over-identification test since there are only 2 variables included in the equation for treatment which are unique to it, implying that the test would have only one degree of freedom. We therefore report a wald test for all coefficients (excluding the fixed effects) in the electricity spending equation being zero. This can only be a heuristic test, since the estimation is actually a composite of essentially two equations. This issue is also noted in (Reiss and White 2005a) who pursue a heuristic approach, using test-of-fit to data, in- and out-of-sample.

58 Results using raw electricity spending data did not alter the qualitative nature of the results, nor even the significance levels. The coefficient on the "endogenous binary variable", $A_{i}$, tended to take values that were very close to the mean electricity spending in the sample. The reason for this was that the mean is highly impacted by the very low values in electricity spending (in many cases, unbelievably so). An alternative explored was to replace electricity spending with its Winsorized version, with the top and bottom $5 \%$ of values replaced by the 5 th percentile from the top and bottom. This estimator yielded arguably more plausible (lower) estimates. Thus, our results here are not sensitive to the form of electricity spending variable used. 
We quickly summarize our prior expectations regarding the signs on different coefficients: we anticipate a small but positive income elasticity (anywhere from 0.1 to 0.6 , based on prior literature), and we anticipate Owner-occupiers to have slightly higher consumption. Age, sex, education and location in an urban area are typically anticipated to reduce consumption, while size of household and home are typically thought as proxying for disposable income, with a tendency to increase consumption. Finally, being member of an environmental organization and the ability to identify an energy label, proxying for awareness of, and concern towards, environmental issues, are thought to have a tendency to reduce consumption.

Consider first the results from the raw data, in Column II. We find plausible income elasticity, of 0.14 , interpreted as $0.14 \%$ increase in electricity consumption for every percentage increase in income. While at the lower end of the empirically reported estimates (Kriström 2013), these are nonetheless very plausible short-run estimates. Household size, which we (in common with the literature) interpret as a proxy for total disposable income, is substantially positive; so too is the estimate of home size. Interestingly, we find support for prior empirical results, that multi-dwelling residences consume less energy than isolated ones, and so too do individuals who live in urban areas.

Older individuals do tend to consume a bit more, again confirming prior findings. Finally, ability to identify an energy label does not appear to be substantially indicative of any particular attitude that is not already captured by an important attitudinal variable, membership in an environmental organization. Finally, those who "purchase" an energy-efficient appliance tend to have significantly lower energy consumption. It is illustrative, and indicative of the magnitude of the bias induced by an OLS regression, to note that OLS regression tended to produce a coefficient on energy efficient appliance ownership that was positive (albeit not significant).

Consider now the regression with imputed values used. Two facts are apparent from Column III: first, some coefficients increase in magnitude (income elasticity) while others are reduced, but all changes are rather small, and second, that there is no change in sign or significance on any coefficient. This also provides some heuristic support for the validity of the imputation approach used.

In summary, plausible income elasticities were estimated, and certain behavioural indicators, particularly membership in an environmental organization, were shown to substantially impact electricity consumption. In particular, ownership of an energy efficient appliance was shown to be associated with reduced electricity consumption. 


\section{POLICY IMPLICATIONS}

Energy policies in use to promote energy efficiency and renewable energy include a large variety of various incentives such as feed-in tariffs and certificate systems, but there are also many other non-price instruments such as regulations on buildings and appliances ${ }^{59}$ and information-based instruments. Policy recommendations are offered in, inter alia, Jaffe and Stavins (1994), Policy Studies Institute (2006) and Gillingham, Newell, and Palmer (2009). Jaffe and Stavins (1994) follows the traditional delineation using market failures as the indicator; hence high discount rates, private cost of information acquisition and heterogeneity of potential adopters do not motivate government intervention (Jaffe and Stavins (1994, p. 111). Their list of market failures (in italics) and suggested instruments include:

1. Incomplete information, motivating energy audits, product labeling requirements, disclosure for new buildings and public information campaigns;

2. Principal agent problems, suggesting home energy rating systems, audit and disclosure standards;

3. Direct subsidies to fossil fuels ${ }^{60}$, which is better described as a policy failure;

4. Remaining externalities, internalize e.g. via taxes;

5. Insufficient $R \& D$, government support; and,

6. Adoption externalities, subsidies, tax credits.

The Policy Studies Institute (2006) stresses insights from behavioral economics and marketing; indeed, the primary advice is to disbelieve the standard model of the consumer in economics. The recommendations include: (i) improve policy evaluation (ii) develop an international evidence base and (iii) look for ways to target policies.

\footnotetext{
${ }^{59}$ As noted, whether or not energy efficiency policy is needed at all remains debated. IEA (2010) has released a report entitled "efficiency policies and programmes in IEA countries: learning from the critiques". According to the report, the following critiques have been raised against energy efficiency policies:

- the rebound effect will erode most or all energy savings

- the economy-wide effect will also erode energy savings

- most energy savings would happen anyway due to ongoing technological advances or rising energy prices

- the discount rates used to justify energy efficiency policies and programmes are too low

- ratepayer- or taxpayer-funded energy efficiency programmes are an unfair subsidy that hurts nonparticipants and low-income households

- the market failures frequently used to justify energy efficiency policies and programmes are mostly a myth

${ }^{60}$ Sovacool (2009) interviews more than 100 stakeholders in the energy policy area from Asia, Europe and NorthAmerica (they "were selected to represent the diverse array of stakeholders in the electricity sector," (p. 1539)) and finds that "removing subsidies" tops the list of preferable measures to support energy efficiency and renewable energy. The second ranked is policies to "create accurate electricity prices and encourage feedback" (the third is a national feed-in tariff).
} 
The sheer amount of material ${ }^{61}$ makes it difficult to make an all-encompassing assessment of what we know and then map this into suggestions about how to best shape policy in this area. Economists can point to the bulk of evidence showing that prices do affect behavior and most economists would agree with the proposition that any instrument should target the source of the problem as closely as possible. Thus, if the main problem with the use of energy is externalities, then we should target the externalities (and use price instruments). If the main problem is energy use per se, the conclusion is the same from an efficiency point of view; raise the price to limit consumption. Researchers from other disciplines do not always share this view - see e.g. Stern (1992) - and provide arguments that, as we have seen, support the use of non-price instruments, not the least in terms of reducing energy use per se.

Our literature review has provided several encouraging examples of the usefulness of non-price instruments and throughout this project we have remained cautiously positive towards them. The additional evidence that is now available does not weaken the case for the non-price instruments, but neither does the evidence weaken the case for what remains the default option for efficiency, namely incentive based instruments.

Based on the literature reviewed and the insights gained from analysis of the data in the EPIC study, policy conclusions include the following:

- Make policy objectives clear. Theory and experience suggests that negative externalities are better attacked directly and not indirectly via energy savings. There are, of course, other reasons for reducing energy demand.

- Changes take time. The literature clearly shows that the short-run response is slow, but the longrun response to energy and environmental policy could be significant.

- Policy targeting and heterogeneity. The heterogeneity documented here and elsewhere regarding policy response in the residential sector underscores the usefulness of looking beyond averages.

- Rebound effects should be considered. Results vary across studies regarding the severity of the rebound effect, i.e. the fact that energy efficiency policies may increase rather than decrease energy demand. The most detailed studies suggest that it might be small, but this all depends on the chosen system boundary. A policy that promotes energy-efficiency benefits should include analysis of the rebound effect under an explicitly stated system boundary.

- Soft vs. hard policy instruments. Taxes and other incentive-based instruments work well according to theory and evidence. Studies on the potential usefulness of softer instruments such as information, labeling and descriptive norms is mounting. Overall, a more positive picture about the usefulness of these instruments is emerging, consistent with the views in OECD (2011).

- Approach policies in a holistic manner. In particular, it is important to consider energy and environmental policies holistically. For example, reducing climate change by converting to renewable energy may make it more difficult to reach an energy efficiency goal (for example, an environmentally more benign fuel could be less energy efficient). The traditional, and still useful, rule is to align the number of policy goals with the number of policy instruments.

\footnotetext{
${ }^{61}$ See Vine (2008) for an overview of the literature evaluating energy efficiency programs.
} 


\section{CONCLUSIONS}

We have developed econometric models that cater for missing values and complex survey structure (i.e. weighting). Importantly, we have tried to address the substantial heterogeneity that we know exists in this type of multi-country survey. Our econometric analysis covers three general areas; WTP for green energy, owner/tenant decisions on energy efficiency, and electricity consumption.

First, the 2011 EPIC survey, the earlier one and the extant literature on WTP for green energy suggest that the valuations are not overwhelmingly large (seldom larger than $10 \%$ of the bill) and that noneconomic factors, and, especially, membership in an environmental organization, are more important than economic factors when understanding them. Second, as expected, we find in this survey an "owner-effect" regarding the investment in energy efficient equipment. Insofar as substantial investment in green energy implies higher energy prices, these results should provide food for thought when decision-makers in different countries are contemplating future energy policy. Indeed, these results hold across a range of countries, as the OECD EPIC surveys have shown.

The average WTP across both surveys is less than $10 \%$ of the electricity bill for a complete overhaul of the energy system into one based on renewables. This valuation varies considerably across households. Detailed analysis of both surveys singles out a consistently significant variable; membership in an environmental organization (which increases WTP - in a statistical sense - regardless of income, country of origin, household size and composition etc.). Other variables are not as stable across statistical models. It is apparent that membership in an environmental organization is a proxy for several environmental behaviours; in this survey, we see it in a hypothetical market for a renewable energy switch and also in the market for electricity. Members are likely to want to pay more for renewable energy and consume less electricity, everything else being equal.

There are other attitudinal factors of importance such as the energy behavioural index, yet no other variable displays such consistency. Income, perhaps surprisingly, affects the probability of entering the (hypothetical) market, but generally not the level of WTP. We also found that the importance of different background variables vary across the level of valuation and documented that age has a different impact than displayed in the traditional Tobit-style models. This finding illustrates the usefulness of looking beyond the average effects, as the Tobit-style models do.

Our analysis of energy efficiency focused on the owner/tenant divide, appliance decision and grants. We find an "Owner" effect in the purchase (owning) of energy efficient devices across a range of devices, with a substantially larger magnitude of the effect for relatively immobile investments (such as windows and thermal insulation). It is only with energy efficient windows and thermal insulation that substantial differences are apparent (15\% and $19 \%$ respectively).

The income elasticity of electricity demand is estimated at 0.14 , consistent with conventional wisdom, at least if interpreted as a short-run elasticity. This also indicates that increasing electricity prices tend to have a regressive impact. Household size, a proxy for disposable income, has a strongly positive impact on demand. Multi-dwelling residences consume less energy than isolated ones, and so too do individuals who live in urban areas. Membership in an environmental organisation is, as noted, strongly related to electricity consumption.

Turning now to policy variable in more detail, the descriptive analysis in OECD (2014) indicated that ability to identify an energy label lowered energy consumption, although the effect was small. However, the formal econometric modelling undertaken here did not substantiate this finding. To further buttress the impact of labels we need more precise information about appliance investments. Furthermore, because 
roughly $90 \%$ of the households report individual metering, it is difficult to predict the effect of metering on consumption and behavioural practices in general. Conditional on purchasing an energy efficient device, tenants are as likely as owner-occupiers to apply for a government grant. We find exceptions for "thermal insulation" and "wind turbines", but the data is too sparse to allow robust statistical tests.

Insofar as the EPIC survey goes, we have yet to determine a strong impact of softer instruments like labelling and information. Our literature review did, however, paint a rather more positive view towards information, especially if contextual. Detailed studies suggest that contextual information, such as including information in the electricity bill about neighbourhood consumption, makes a difference. Possibly, our findings may be affected by self-selection (e.g. we may not be able to see all cases when contextual information plays no role due the difficulty of publishing negative results). Even so, the evidence is mounting and cannot be disregarded. 


\section{REFERENCES}

Abdullah, S. and P.W. Jeanty (2011), "Willingness to Pay for Renewable Energy: Evidence from a Contingent Valuation Survey in Kenya", Renewable and Sustainable Energy Reviews 15 (6): 29742983.

Abrahamse, W., et al. (2005), "A review of intervention studies aimed at household energy conservation", Journal of Environmental Psychology, Vol. 25, pp. 273-291.

Allcott, H. (2009), “Social Norms and Energy Conservation”, CEEPR Working Paper, MIT.

Allcott, H. (2011), "Social Norms and Energy Conservation." Journal of Public Economics, 95 (9-10) (October): 1082-1095. doi:10.1016/j.jpubeco.2011.03.003.

Amir, O., et al. (2005), "Psychology, Behavioral Economics, and Public Policy." Marketing Letters, 16 (3-4) (December 1). http://escholarship.org/uc/item/5bv261k5.

Andersson, Bo. (1997), "Essay on Energy Economics". PhD-thesis, Stockholm: Stockholm School of Economics.

Ayres, I., S; Raseman and A; Shih (2012), "Evidence from Two Large Field Experiments That Peer Comparison Feedback Can Reduce Residential Energy Usage", Journal of Law, Economics, and Organization (August 20). doi:10.1093/jleo/ews020. http://jleo.oxfordjournals.org/content/early/2012/08/18/jleo.ews020.

Baker, E. (2012), "Option Value and the Diffusion of Energy Efficient Products", The Energy Journal, 33 (4) (October 1). doi:10.5547/01956574.33.4.3.

http://www.iaee.org/en/publications/ejarticle.aspx $2 \mathrm{id}=2495$.

Borenstein, S. (2012), "The Private and Public Economies of Renewable Electricity Generation", The Journal of Economic Perspectives 26 (1) (January 1): 67-92.

Brounen, D., N. Kok and J.M. Quigley (2011), "Residential Energy Use and Conservation: Economics and Demographics", Eur Econ Rev (forthcoming). http://www.corporateengagement.com/files/publication/BKQ\%20Energy\%20072711.pdf.

Brown, Z. (2014), "Greening Household Behaviour: Cross-domain comparisons in environmental attitudes and behaviours", OECD Environment Working Papers, No. 68, OECD Publishing, Paris, http://dx.doi.org/ 10.1787/19970900.

Brown, Z., et al. (2013), "Testing the effect of defaults on the thermostat settings of OECD employees", Energy Economics, Volume 39, September 2013, Pages 128-134.

Cameron, T.A. (1985), "A Nested Logit Model of Energy Conservation Activity by Owner-occupiers of Existing Single Family Dwellings", The Review of Economics and Statistics, 67 (2) (May 1): 205211. doi:10.2307/1924719. 
Chernozhukov, V., I. Fernández-Val and A.E. Kowalski (2011), "Quantile Regression with Censoring and Endogeneity", Working Paper, National Bureau of Economic Research. http://www.nber.org/papers/w16997.

Dargay, J. (2008), , "Effects of Taxation on Energy Demand" report to Swedish Remit on Energy Efficiency, SOU 2008:110. Statens Offenteliga Utredningar (SOU). Stockholm: Ministry of Enterprise.

Davis, L.W. (2008), "Durable Goods and Residential Demand for Energy and Water: Evidence from a Field Trial", The RAND Journal of Economics, 39 (2) (July 1): 530-546.

Davis, L.W. (2011), "Evaluating the Slow Adoption of Energy Efficient Investments: Are Tenants Less Likely to Have Energy Efficient Appliances?", NBER Working Papers.

De Almeida, A., et al. (2011), "Characterization of the household electricity consumption in the EU, potential energy savings and specific policy recommendations", Energy and Buildings, 1884-1894, dx.doi.org/10.1016/j.enbuild.2011.03.027.

Dubin, J.A. and D.L. McFadden (1984), “An Econometric Analysis of Residential Electric Appliance Holdings and Consumption”, Econometrica, 52 (2) (March): 345. doi:10.2307/1911493.

Ehreke, I., B. Jaeggi and K. W. Axhausen (2014), "Greening Household Behaviour and Transport", OECD Environment Working Papers, No. 77, OECD Publishing, Paris, http://dx.doi.org/ 10.1787/19970900.

Ek, K. and P. Söderholm (2008), "Norms and Economic Motivation in the Swedish Green Electricity Market”, Ecological Economics, 68 (1-2) (December 1): 169-182.

doi:10.1016/j.ecolecon.2008.02.013.

Ek, K. and P. Söderholm (2010), "The Devil Is in the Details: Household Electricity Saving Behavior and the Role of Information", Energy Policy, 38 (3) (March): 1578-1587. doi:10.1016/j.enpol.2009.11.041.

Ertör-Akyazı, P., et al. (2012), "Citizens' Preferences on Nuclear and Renewable Energy Sources: Evidence from Turkey”, Energy Policy, 47 (August): 309-320. doi:10.1016/j.enpol.2012.04.072.

Frederick, S., G. Loewenstein and T. O'Donoghue (2002), “Time Discounting and Time Preference: A Critical Review", Journal of Economic Literature, 40 (2) (June 1): 351-401.

Gales, B., et al. (2007), "North Versus South: Energy Transition and Energy Intensity in Europe over 200 Years", European Review of Economic History, 11 (2) (August 1): 219-253. doi:10.1017/S1361491607001967.

Gerpott, T.J. and I. Mahmudova (2010), "Determinants of Price Mark-up Tolerance for Green Electricity Lessons for Environmental Marketing Strategies from a Study of Residential Electricity Customers in Germany", Business Strategy and the Environment 19 (5): 304-318. doi:10.1002/bse.646.

Gillingham, K., R.G. Newell and K. Palmer (2009), "Energy Efficiency Economics and Policy", Annual Review of Resource Economics, 1 (1): 597-620. doi:10.1146/annurev.resource.102308.124234.

Gordon, R.L. (2009), “The Theory and Practice of Energy Policy”, International Handbook on the Economics of Energy. 
Gsottbauer, E. and J.C.J.M. Bergh (2010), "Environmental Policy Theory Given Bounded Rationality and Other-regarding Preferences", Environmental and Resource Economics, 49 (2) (December 4): 263304. doi:10.1007/s10640-010-9433-y.

Hanemann, W.M. (1984), "Discrete/Continuous Models of Consumer Demand", Econometrica, 52 (3) (May): 541. doi:10.2307/1913464.

Hansla, A. (2011), "Value Orientation and Framing as Determinants of Stated Willingness To Pay for EcoLabeled Electricity", Energy Efficiency, 4(2), 185-192 doi:10.1007/s12053-010-9096-0.

Hartman, RS. (1979) "Frontiers in Energy Demand Modeling", Annual Review of Energy, 4 (1): 433-466. doi:10.1146/annurev.eg.04.110179.002245.

Hassett, K.A. and G.E. Metcalf (1993), "Energy Conservation Investment: Do Consumers Discount the Future Correctly?", Energy Policy, 21 (6) (June): 710-716. doi:10.1016/0301-4215(93)90294-P.

Hassett, K.A. and G.E. Metcalf (1995), "Energy Tax Credits and Residential Conservation Investment: Evidence from Panel Data", Journal of Public Economics, 57 (2) (June): 201-217. doi:10.1016/0047-2727(94)01452-T.

Hausman, J.A. (1979), "Individual Discount Rates and the Purchase and Utilization of Energy-Using Durables", The Bell Journal of Economics, 10 (1) (April 1): 33-54. doi:10.2307/3003318.

IEA/OECD (2007), "Mind the Gap: Quantifying Principal Agent Problems in Energy Efficiency", Paris: IEA. http://www.iea.org/publications/freepublications/publication/mind_the_gap.pdf.

Jaffe, A.B. and R.N. Stavins (1994), “The Energy-efficiency Gap What Does It Mean?”, Energy Policy, 22 (10): 804 - 810. doi:DOI: 10.1016/0301-4215(94)90138-4.

Kempton, W. and L. Montgomery (1982), "Folk Quantification of Energy", Energy, 7 (10) (October): 817-827. doi:10.1016/0360-5442(82)90030-5.

Koenker, R. (2005), "Quantile regression", Cambridge; New York: Cambridge University Press.

Kriström, B. (2013), "Residential Energy Demand", In Encyclopedia of Environmental and Resource Economics, ed. Jason Shogren. Elsevier: Elsevier.

Liddle, B. (2012), “Breaks and Trends in OECD Countries' energy-GDP Ratios”, Energy Policy, 45 (June): 502-509. doi:10.1016/j.enpol.2012.02.061.

Linares, P. and X. Labandeira (2010), "Energy Efficiency: Economics and Policy", Journal of Economic Surveys, 24 (3): 573-592. doi:10.1111/j.1467-6419.2009.00609.x.

Lutzenheiser, L. (1993), "Social and Behavioral Aspects of Energy Use", Annual Review of Energy and the Environment, 18. Annual Reviews: 247-89.

Mäler, K.G. (1977), "Varför Energipolitik” Ekonomisk Debatt 4: 423-428.

Martinsson, J., L. Lundquist and A. Sundström (2011), "Energy Saving in Swedish Households. The (relative) Importance of Environmental Attitudes", Energy Policy, 39: 5182-5191. 
Millock, K. (2014), "Greening Household Behaviour and Food", OECD Environment Working Papers, No. 75, OECD Publishing, Paris, http://dx.doi.org/ 10.1787/19970900.

Mundaca, L., et al. (2010), "Evaluating Energy Efficiency Policies with Energy-Economy Models", Journal Name: Annual Review of Environment and Resources, Medium: ED; Size: 47.

Nauges, C. (2014), "Greening Household Behaviour and Water", OECD Environment Working Papers, No. 73, OECD Publishing, Paris, http://dx.doi.org/ 10.1787/19970900.

Nolan, J.M., (2008), “Normative Social Influence Is Undetected”, Personality and Social Psychology Bulletin, 34 (7) (July 1): 913-923. doi:10.1177/0146167208316691.

OECD (2006), "The Distributional Effects of Environmental Policy", Serret, Y. and N. Johnstone (eds.), OECD, Paris/Edward Elgar Publishing, Cheltenham, UK.

OECD (2014), Greening Household Behaviour: Overview from the 2011 Survey - Revised edition, OECD Studies on Environmental Policy and Household Behaviour, OECD Publishing, Paris, http://dx.doi.org/10.1787/9789264214651-en.

OECD (2011), Greening Household Behaviour: The Role of Public Policy, OECD Studies on Environmental Policy and Household Behaviour, OECD Publishing, Paris, http://dx.doi.org/10.1787/9789264096875-en.

Oliver, H., J. Volschenk and E. Smit (2011), "Residential Consumers in the Cape Peninsula's Willingness to Pay for Premium Priced Green Electricity”, Energy Policy, 39 (2) (February): 544-550. doi:10.1016/j.enpol.2010.10.012.

Owens, S. and L. Driffill (2008), "How to Change Attitudes and Behaviours in the Context of Energy", Energy Policy, 36 (12) (December): 4412-4418. doi:10.1016/j.enpol.2008.09.031.

Ozaki, R. (2011), "Adopting sustainable innovation: what makes consumers sign up to green electricity?", Business Strategy \& the Environment, 20 (191, 1-17, doi: 10.1002/bse.650.

Palatnik, R.R. et al. (2014), "Greening Household Behaviour and Waste”, OECD Environment Working Papers, No. 76, OECD Publishing, Paris, http://dx.doi.org/ 10.1787/19970900.

Policy studies institute (2006), "Designing Policy to Influence Consumers: Consumer Behaviour Relaring to the Purchasing of Enfironmentally Prefereable Goods", EU Environment Report. http://ec.europa.eu/environment/enveco/pdf/RealWorldConsumerBehaviour.pdf.

Poortinga, W., L. Steg and C. Vlek (2004), "Values, Environmental Concern, and Environmental Behavior A Study into Household Energy Use", Environment and Behavior, 36 (1) (January 1): 70-93. doi:10.1177/0013916503251466.

Reiss, P.C. and M.W. White (2005), "Household Electricity Demand, Revisited", The Review of Economic Studies, 72 (3) (July 1): 853-883.

Reiss, P.C. and M.W. White (2008), "What Changes Energy Consumption? Prices and Public Pressures", The RAND Journal of Economics, 39 (3) (October 1): 636-663. 
Revelt, D. and K. Train (1998), "Mixed Logit with Repeated Choices: Households' Choices of Appliance Efficiency Level”, Review of Economics and Statistics, 80 (4) (November 1): 647-657. doi:10.1162/003465398557735.

Sardianou, E. (2007), "Estimating Energy Conservation Patterns of Greek Households", Energy Policy, 35 (7) (July): 3778-3791. doi:10.1016/j.enpol.2007.01.020.

Serret, Y. and Z. Brown (2014), "Greening household behaviour: Overview of results from econometric analysis and policy implications", OECD Environment Working Papers, No. 79, OECD Publishing, , Paris, http://dx.doi.org/ 10.1787/19970900.

Shogren, J. (2012), "Behavioural Economics and Environmental Incentives", OECD Environment Working Papers, No. 49, OECD Publishing. doi: 10.1787/5k8zwbhqs1xn-en

SOU (2008:110) (2008), "Vägen till Ett Energieffektivare Sverige (Road to a More Energy Efficiennt SWeden)", Government Commission Report. Stockholm: Ministry of Enterprise.

Sovacool, B.K. (2009), "Rejecting Renewables: The Socio-technical Impediments to Renewable Electricity in the United States", Energy Policy, 37 (11) (November): 4500-4513. doi:10.1016/j.enpol.2009.05.073.

Stern, P.C. (1992), "What Psychology Knows About Energy Conservation", American Psychologist, 47 (10): 1224-1232.

Stern, P.C. (2000), "New Environmental Theories: Toward a Coherent Theory of Environmentally Significant Behavior", Journal of Social Issues, 56 (3): 407-424. doi:10.1111/0022-4537.00175.

Strazzera, E., M. Mura and V. Statzu (2012), "Powering the Change: a Contingent Valuation Study on the Determinants of Demand for Green Vs. Brown Energy", Journal of Environmental Economics and Policy, 1 (2): 146-173. doi:10.1080/21606544.2012.692864.

Sutherland, R.J. (1991), “Market Barriers to Energy-Efficiency Investments”, The Energy Journal, 12 (3): $15-34$.

Vine, E. (2008), "Breaking down the Silos: The Integration of Energy Efficiency, Renewable Energy, Demand Response and Climate Change", Energy Efficiency, 1 (1): 49-63. doi:10.1007/s12053-0089004-z.

Wilson, C. and H. Dowlatabadi (2007), "Models of Decision Making and Residential Energy Use", Annual Review of Environment and Resources, 32 (1): 169-203. doi:10.1146/annurev.energy.32.053006.141137.

Zhai, P. and E.D. Williams (2012), "Analyzing Consumer Acceptance of Photovoltaics (PV) Using Fuzzy Logic Model”, Renewable Energy, 41 (May): 350-357. doi:10.1016/j.renene.2011.11.041.

Zorić, J. and N. Hrovatin (2012), "Household Willingness to Pay for Green Electricity in Slovenia", Energy Policy, 47 (August): 180-187. doi:10.1016/j.enpol.2012.04.055. 


\section{APPENDIX: TECHNICAL MATERIAL}

It is well known (see for instance Rao \& Wu (1988), Rao, Wu and Yue (1992), and Shao (2003)) that, in the presence of sample weighting, naïve bootstrap estimators are potentially biased. Only by use of certain types of scalings (moments or weights, depending upon the estimator type, linear versus non-linear) is it possible to obtain unbiased estimators. Given the substantial computational burden of such bootstrap estimators in the relatively complicated non-linear models used in the analyses here, we eschew such (possibly superior) resampling methods in favour of much simpler "Linearization" or "Taylor Series"based variance and standard error estimates in the analysis.

\section{Likelihood and Pseudo-likelihood Estimators and Test Statistics}

In the presence of sampling weights, the maximum likelihood estimation needs to be modified (because each observation has a sample weight attached to it). Maximum likelihood methods in these settings are typically known as "pseudo-" or "weighted-" maximum likelihood estimation (see Chambless and Boyle (1985) and Roberts, Rao, \& Kumar (1987)). In light of the discussion above, the covariance matrix of the estimated coefficients is computed by the linearization method.

In addition, in this framework, the familiar likelihood ratio (LR) test is unavailable, mainly since the sampling distribution of the test statistic (pseudo-likelihood ratio) is likely model specific and is not, as is usual in the unweighted (i.e. i.i.d) data case, $\chi_{1}^{2}$. See Lumley \& Scott (2012) for a discussion and for references). In the absence of this statistic, typically, model selection can be performed using the familiar Wald approach which continues to be valid even in the case of weighted likelihood. Therefore, where appropriate and useful, this is the test statistic (or p-value from such a test) reported throughout the analysis.

\section{Multiple Imputation}

Missing values are a substantial issue in the survey under consideration, in particular in the variable "electricity spending" (approx. 60\% of the sample does not report a number for this variable). This creates two kinds of issues for analysis; first, using the non-missing observations only can lead to inconsistent inference in certain cases and second, even if consistent, inference quality suffers due to loss of (statistical) power i.e. smallness of the sample can lead to issues with estimation, in particular, of variance estimation.

In particular, inferences can be inconsistent and/or biased except when data are missing under what is referred to as Missing Completely at Random (MCAR), a condition under which missing data, in this case $Y_{\text {miss }}$, are missing for reasons which are completely independent of both $X_{i}$ and $Y_{\text {observed }}$. In other words, when data are missing completely randomly, then inference using only missing data is valid; else it is not. See (Schafer, 1999) for some details and a basic overview of the issue. See Little \& Rubin (2002) and Rubin (2004) for technical details and Brownstone \& Valletta (2001) for some applications in economics, typically for improving data quality, rather than for imputing specific missing data.

There are three possible alternatives to an analysis using only complete data, when the objective is obtaining valid inference: imputation (single or multiple), inverse weighting and specific tools for a given task. Since the latter alternative is both quite demanding and not replicable, there are typically only two generic tools used, of which inverse weighting cannot be used in our case. When using imputing however, it is always beneficial to use multiple imputation over a single imputation for complex models, for the 
reason that it is difficult to account for the additional variance induced due to the imputation procedure into the actual post-imputation analysis (a particular issue with substantial missing data (as here) ${ }^{62}$.

An important and convenient feature with multiple imputations is the rather low number of imputations typically recommended for inference: 5-10. The most important feature necessary for imputation methods in general, and MI in particular, to lead to valid inference are that "missingness" ("non-response", in our case) is ignorable i.e. that the probability that observations are missing may depend (possibly) on both covariates and observed values of $\mathrm{Y}$ but not on the missing values themselves. In other words, if observations on electricity spending are missing either because they are too high or too low or follow any specific pattern (after accounting for covariates) then imputing such values does not lead to valid inference. This typically rules out contexts with "selection" so common in economics. However, we observe that in our case, it is unlikely to be an issue as there appears to be no specific pattern to missing data $^{63}$.

The following are the typical steps involved in carrying out an analysis using $\mathrm{MI}^{64}$ :

1. Imputation: Replace missing values with $\boldsymbol{M}$ sets of plausible imputed values $(\boldsymbol{M}>1)$, using an imputation model, obtaining $\boldsymbol{M}$ copies of a complete (as complete as possible) data set.

2. Complete-data-set analysis: Perform analysis on each of the $\boldsymbol{M}$ copies of the data set (e.g. regression on each of $\boldsymbol{M}$ datasets).

3. Pooling for analysis results: Consolidate the results of the $\boldsymbol{M}$ analyses into one unified and coherent result (e.g. a mean set of regression coefficients), taking into account the within (each $\boldsymbol{M})$ and between (across $\boldsymbol{M}$ ) variance.

It is important to note that the additional variance induced by the fact that the $\boldsymbol{M}$ data sets are imputed is explicitly accounted for in this process. For our case, imputations were carried out only for the electricity spending data, using the predictive mean matching method, a partially parametric method that matches the missing value to the observed value with the closest predicted mean (or linear prediction) ${ }^{65}$, based on a combination of a linear regression and a k-nearest neighbor method.

\footnotetext{
${ }^{62}$ This problem is exacerbated for imputing missing values on multiple variables, something not of importance here.

${ }^{63}$ They were not specifically correlated with either income or other obvious patterns, in analysis not reported here.

${ }^{64}$ The conditions under which these steps lead to valid inference are detailed in Rubin (2004) and further elaborated in Meng (1994) and Rubin (1996).

${ }^{65}$ It uses the normal linear regression to obtain linear predictions, which is subsequently used as a distance measure to form the set of nearest neighbors consisting of the complete values. From this, it randomly draws an imputed value. By drawing from the observed data, PMM preserves the distribution of the observed values in the missing part of the data, which can make it more robust than the comparable fully parametric linear regression approach (see the entry on "mi impute pmm" in Stata Manual and Schenker and Taylor (1996) for discussion and details).
} 


\section{ANNEX A}

Table A1. Average Marginal Effects from 2-stage Instrumental Variable (IV) regression of electricity consumption on relevant variables (columns I and III), with the purchase (owning) decision as a binary endogenous variable

\begin{tabular}{|c|c|c|c|c|}
\hline & \multicolumn{2}{|c|}{ With missing values } & \multicolumn{2}{|c|}{ Imputation for missing values } \\
\hline & $\begin{array}{l}\text { Electricity } \\
\text { Equation }\end{array}$ & $\begin{array}{c}\text { Energy Efficiency } \\
\text { Equation }\end{array}$ & $\begin{array}{l}\text { Electricity } \\
\text { Equation }\end{array}$ & $\begin{array}{c}\text { Energy Efficiency } \\
\text { Equation }\end{array}$ \\
\hline \multirow[t]{2}{*}{ Members in household } & $0.124^{\star * *}$ & $0.0240^{* * *}$ & $0.112^{\star \star *}$ & $0.0189^{\star * \star}$ \\
\hline & $(9.66)$ & $(2.75)$ & $(9.86)$ & $(2.70)$ \\
\hline \multirow[t]{2}{*}{ Log (Household income) } & $0.143^{\star \star *}$ & $0.0824^{\star \star *}$ & $0.150^{\star \star \star}$ & $0.0759^{\star \star \star}$ \\
\hline & $(4.27)$ & $(3.75)$ & $(5.52)$ & $(4.39)$ \\
\hline \multirow[t]{2}{*}{ Size of Primary Residence } & $0.000749^{*}$ & 0.000241 & $0.00102^{* * *}$ & $0.000420^{* *}$ \\
\hline & (1.89) & $(1.11)$ & (3.49) & (2.31) \\
\hline \multirow[t]{2}{*}{ Home Type (1=Multi-dwelling) } & $-0.178^{\star *}$ & 0.0252 & $-0.226^{* * *}$ & $0.0378^{*}$ \\
\hline & $(-2.57)$ & $(0.81)$ & $(-5.21)$ & $(1.68)$ \\
\hline \multirow[t]{2}{*}{ Energy consideration Home purchase $(1=\mathrm{Yes})$} & -0.0241 & $0.100^{\star * *}$ & -0.00136 & $0.0886^{\star * *}$ \\
\hline & $(-0.50)$ & $(3.93)$ & $(-0.04)$ & $(4.34)$ \\
\hline \multirow[t]{2}{*}{ Home Owner-occupiership (1=Owner) } & $0.140^{\star * *}$ & $0.0920^{* * *}$ & $0.0784^{\star \star}$ & $0.0652^{\star * *}$ \\
\hline & $(3.03)$ & $(3.44)$ & $(2.34)$ & $(3.21)$ \\
\hline \multirow[t]{2}{*}{ Urban Area (1=Urban) } & $-0.147^{\star \star *}$ & -0.00803 & $-0.134^{\star * *}$ & -0.0220 \\
\hline & $(-2.82)$ & $(-0.30)$ & $(-3.63)$ & $(-1.07)$ \\
\hline \multirow[t]{2}{*}{ Age of $\mathrm{HH}$ head } & $0.00318^{*}$ & 0.00101 & $0.00322^{* *}$ & 0.00110 \\
\hline & $(1.76)$ & $(1.11)$ & $(2.50)$ & $(1.58)$ \\
\hline \multirow[t]{2}{*}{ Gender ( $1=$ Male) } & 0.0546 & -0.0148 & 0.0401 & -0.00788 \\
\hline & $(1.32)$ & $(-0.64)$ & $(1.29)$ & $(-0.44)$ \\
\hline \multirow[t]{2}{*}{ Years of Post-Secondary Education } & 0.0115 & -0.00199 & 0.00794 & -0.00338 \\
\hline & $(1.23)$ & $(-0.39)$ & $(1.19)$ & $(-0.85)$ \\
\hline \multirow[t]{2}{*}{ Employment Status (1=Employed) } & -0.0466 & -0.0348 & -0.0523 & -0.0196 \\
\hline & $(-1.04)$ & $(-1.38)$ & $(-1.47)$ & $(-1.00)$ \\
\hline \multirow[t]{2}{*}{ Identify Energy Efficiency Label? } & -0.0223 & & -0.0399 & \\
\hline & $(-0.46)$ & & $(-1.08)$ & \\
\hline \multirow[t]{2}{*}{ Energy Efficient Appliances } & $-0.350^{* *}$ & & $-0.419^{* * *}$ & \\
\hline & $(-2.34)$ & & $(-3.03)$ & \\
\hline \multirow[t]{2}{*}{ Member of Envt. Organisation } & $-0.0493^{*}$ & $0.149^{\star \star *}$ & $-0.0391^{*}$ & $0.0969^{* \star *}$ \\
\hline & $(-1.68)$ & $(3.45)$ & $(-1.95)$ & (2.58) \\
\hline \multirow[t]{2}{*}{ Energy Behaviour Index } & & $0.0217^{\star \star *}$ & & $0.0229^{\star * *}$ \\
\hline & & $(2.96)$ & & $(4.30)$ \\
\hline Index of Concern for CC & & $\begin{array}{c}-0.000555 \\
(-0.09)\end{array}$ & & $\begin{array}{c}-0.00553 \\
(-1.11)\end{array}$ \\
\hline Observations & 4651 & 4651 & 7365 & 7365 \\
\hline
\end{tabular}

Note: A treatment effects IV framework is adopted to deal with the endogeneity of the decision to purchase (own) a top-rated energy efficient device. The framework consists of a first stage probit regression for determinants of owning an energy efficient device (labeled "Energy Efficiency Equation"), followed by a second-stage "main equation" (labeled "Energy Equation"). The two equations are jointly estimated using the ML approach (see text). Column I consists of the average marginal effects from the "main" regression, and Column II consists of AME from the probit regression. Columns I and II are the results from a regression with no imputation for missing values of electricity consumption, while Columns III and IV use raw data for missing values for electricity consumption along with missing values for data imputed using methods indicated in the text. All regressions include country-fixed effects (coefficients not reported) and take into account the complex survey nature of the data (i.e. account for sampling weights and report appropriate standard errors). 


\section{ANNEX B: WILLINGNESS TO PAY - ECONOMETRIC METHODS}

We analyse data on the WTP for Green Energy, as a percent of the current electricity bill. We seek to understand two factors, in particular; first, to explore some of the presumptive determinants of WTP and second, to understand how important responses of a 0 WTP are. In general, in the context of WTP, 0 indicates a "corner solution" to the optimisation problem the consumer may be thought as solving, and thus, this choice can have substantial information content ${ }^{66}$.

There are well known issues in dealing with zero-truncated data, in particular when 0 does not represent a "missing data" or "selection" interpretation. In most cases, interest centres on an understanding of two issues: factors which influence non-zero choices (i.e. $\mathrm{P}(y>0 \mid X))$ ) and, conditional on making a non-zero choice, some features of the distribution $f(y \mid X)$ (or $F(y \mid X)$ ), typically taken to be the mean $\mathrm{E}(y \mid X, y>0)$. Thus, one may analyse, for instance, impact of a covariate on the mean WTP (in the current context) conditional on covariates and on observed (stated) positive choice of WTP.

Yet, existing methods in general are highly parametric and in addition, suffer from drawbacks such as lack of robustness to (say) heteroscedasticity ${ }^{67}$. In addition, when data are likely drawn from different countries and contexts, with country-specific factors only imperfectly captured, an important question that arises is of unobserved heterogeneity ${ }^{68}$. The QR framework accommodates heterogeneity in say income responsiveness along the unobserved dimension ${ }^{69}$ (of the quantile). For e.g. data on individual level prices are missing here, and (making the strong) assumption that this is the only important variable missing, one can interpret the coefficient on income as income responsiveness at varying quantiles of the price distribution. Assuming that the mean impact is the focus of interest essentially rules out such scenarios (since the conditional quantiles are parallel shifts).

In summary, existing methods of modelling the conditional mean from a decision variable with a substantial mass at "0" are unsatisfactory for a variety of reasons, and do not provide a comprehensive way of dealing with censoring and heterogeneity. There have been very few attempts at jointly addressing both issues introduced, censoring and heterogeneity, in general; Kowalski (2009), using the framework

${ }^{66}$ Yu \& Abler (2010) identify two distinct reasons for "0" WTP: "protest zeros" (with the individuals feeling that they should not be paying extra for the good, for e.g., while having a possibly non-zero valuation of the good), and "true zeros" (in which respondents actually value the added benefits as zero).

${ }^{67}$ In case of two-stage models, such as the hurdle and tobit, or even the binary dependent variable models, such as probit and logit, ignoring both unobserved heterogeneity and heteroscedasticity can lead to inconsistent parameter estimates, a much more serious issue than standard errors, which is typically what are inconsistent in the linear regression case. This is true irrespective of the parametric estimation framework (LS, ML or GMM).

${ }^{68}$ Typically, when eliciting WTP with the CV method, a random parameters approach is available for certain model frameworks to accommodate unobserved heterogeneity (eg. (Carlsson \& Martinsson, 2004, 2008)). However, it is typically not possible to allow, in a comprehensive framework, both of these features we accommodate here, without making many more assumptions on the parametric forms.

${ }^{69}$ Observe that it is straight forward to allow for heterogeneity along observed dimensions by simply interacting the relevant dimension e.g. income with say urban residence, something which we do not pursue here. 
developed in Chernozhukov et al. (2011b), unify these features ${ }^{70}$. We briefly outline a few of the advantages of such a unified modelling of these two aspects. First, it is possible to obtain elasticity of income across the whole conditional distribution of WTP $^{71}$. Second, unlike traditional two-part or hurdle models for censored data, it is not necessary to understand the "nature" the zeros (see discussion above), since the Censored QR estimator is identical in all cases and censoring is handled nonparametrically. Finally, unobserved individual heterogeneity is addressed as a part of the framework, obviating the need to use a different framework for addressing that issue.

We provide here a brief idea of how the CQR estimator works, and refer to the Appendix for a few details. Two essential elements motivate the CQR approach; first, similar to the mean regression, censoring induces a bias in coefficients (at all quantiles, in this case) but unlike the mean case, uncensored conditional quantiles are in principle easily recovered, since max (Quantile) is the same as the Quantile $(\max )$, a property not shared by the mean ${ }^{72}$. Second, the direct application of the "max" operator renders the otherwise convex problem non-convex and significantly increases the computational burden. Therefore Chernozhukov, Fernández-Val, \& Kowalski (2011b) use the following three-step idea: first, a fraction of the observations most likely to be uncensored (based upon a probit or logit) are retained and second, these are used for the normal $\mathrm{QR}$, and based on predicted values from this regression, a larger set of observations are retained for yet another $\mathrm{QR}$. As always, we report average marginal effects for each covariate i.e. we report $\frac{\partial Q_{\tau}(W T P \mid X)}{\partial X_{j}}$, where $Q_{\tau}(W T P \mid X)$ is read as the $\tau^{\text {th }}$ conditional quantile of WTP.

\footnotetext{
${ }^{70}$ Along with endogeneity, an issue we do not touch upon here.

${ }^{71}$ See Hanemann (1984) for a discussion of such elasticities,

${ }^{72}$ In other words, quantiles are equivariant to monotone transformations i.e. $Q_{h(Y)}=h(Q(Y))$ whenever $h$ is a monotonic function, an example of which is $h()=.\max [$.$] . The same is not true of the expectation$ operation i.e. $E_{h(Y)} \neq h(E(Y))$ for most functions $h$, monotonic or not.
} 


\section{ANNEX C: DIFFERENCES BETWEEN THE TOBIT, CRAGG'S TRUNCATED NORMAL HURDLE MODEL AND THE EXPONENTIAL TYPE II TOBIT (ET2T) MODELS}

We provide a very brief descriptions of the differences between these three models, a more detailed description of which may be found in, for instance Wooldridge (2010, chap. 17), Jones (1992), among others. We introduce two new variables, $Y_{i}$ being the observed WTP, $W^{*}$ the unobserved latent variable which determines WTP, and $s_{i}$ an indicator for $Y_{i}=0 . Y_{i}$ is determined as

$$
Y_{i}=s . W^{*} \quad(0.1)
$$

Two-part models (hurdle models) make one of two assumptions; the more restrictive

$$
D\left(W^{*} \mid s, X\right)=D\left(W^{*} \mid X\right)
$$

With $D(. \mid$.$) a conditional distribution, or the less restrictive$

$$
\mathrm{E}\left(W^{*} \mid s, X\right)=\mathrm{E}\left(W^{*} \mid X\right)
$$

Using the latter, therefore, the equation of interest is

$$
\mathrm{E}\left(Y_{i} \mid s_{i}, X_{i}\right)=s_{i} \mathrm{E}\left(W_{i}^{*} \mid s_{i}, X_{i}\right)=s_{i} \mathrm{E}\left(W_{i}^{*} \mid X_{i}\right)
$$

When $s=1$, eqn (1.3) is simply

$$
\mathrm{E}\left(W^{*} \mid X\right)=\mathrm{E}(Y \mid X, Y>0)
$$

and using the law of iterated expectations and eqn (1.3),

$$
\mathrm{E}\left(Y_{i} \mid X_{i}\right)=\mathrm{E}\left(s_{i} \mid X_{i}\right) \mathrm{E}\left(W_{i}^{*} \mid X_{i}\right)=P\left(s_{i}=1 \mid X_{i}\right) \mathrm{E}\left(W_{i}^{*} \mid X_{i}\right)
$$

Cragg's truncated normal hurdle model is essentially eqn (1.5), with two assumptions: $W^{*}$ is distributed as truncated normal, defined on $\in(0, \infty)$ and $P(s=1 \mid X)=\Phi(X \beta)$ i.e. a probit model, and the two parts of the model in eqn (1.5) have independent parameters. Thus, the probit can be estimated independently of the truncated regression for $Y_{i} \mid Y_{i}>0$. This also explains why the number of observations used in the probit and the truncated regression parts are different for the TNH model, in the tables reported above.

To understand the ET2T model, consider instead the following log normal hurdle model;

$$
Y_{i}=s \cdot W^{*}=\mathrm{I}(X \gamma+v>0) \exp (X \beta+u)
$$


With $v \mid X \sim N(0,1)$ (as is typical in probit models) and $u \mid X \sim N\left(0, \sigma^{2}\right)$. This last implies, in particular, that $W^{*}=\exp (X \beta+u)$ has a $\log$ normal distribution. When $v \mid X$ and $\mathrm{u} \mid \mathrm{X}$ are uncorrelated, then the model is a $\log$ normal hurdle model. With $v \mid X$ and $\mathrm{u} \mid \mathrm{X}$ being correlated, the ET2T model is obtained. The derivation of the likelihood function is a bit involved, see (Wooldridge, 2010, chap. $17 \mathrm{pp}$ 697-98) and is very much like that in the Heckman selection model, labelled the Tobit Type II model. The main issue involved here, as in the Heckman-style models, is that for proper identification, the two sets of covariates in the participation and amount decisions must differ in at least one dimension. Again, similar to the tobit model, due to the joint estimation of both the participation and amount decisions, the number of observations used will be identical for the two tables in the main text (tables 5 and 6 ) for this particular method. 


\section{ANNEX D: DATA SOURCES AND LIMITATIONS}

Based on a sample of more than 12000 respondents in eleven countries, ${ }^{73}$ this thematic report summarises main results on energy from the 2011 OECD periodic surveys on Environmental Policy and Individual Behaviour Change (EPIC) and draws evidence-based policy recommendations. ${ }^{74}$ It builds on earlier work and supplements the overview of the 2011 survey data presented in OECD (2014). ${ }^{75}$

As in all studies involving primary data collection, there can be a sample bias when implementing a survey. Rigorous efforts were made at stratification and quota sampling. The sampling strategy involved stratification across region, gender, age and socio-economic status. The degree to which the country-level samples are representative of the national population is presented for a number of key variables in OECD (2014) in Annex B. However, in some countries (e.g. Chile and Switzerland) not all of these parameters could be included. Nonetheless, as Annex B in OECD (2014) shows, deviations in excess of 20per cent from representativity across these variables, for which quotas were set, were very limited. Response bias can be a second concern. It should be noted that such a bias is not specific to using internet panel-based surveys and responses can be biased by the interviewer in face-to-face interviews and telephone surveys. Given that the subject matter of the OECD survey is not related to information technologies or Internet, except for a very small number of questions (i.e. investment in "smart" meters), there is little reason to believe that this would result in a systematic bias.

It is also important for the reader to bear in mind the fact that all of the data used in the analyses reported here are based upon survey responses. This survey elicited respondents' stated preferences and perceptions. Therefore statistics reported here which relate to objective, verifiable indicators should be interpreted with caution and in some cases there may be 'measurement error'. On the one hand, this may relate to the dependent variable used in the studies. For example, estimates of waste generation and recycling rates may be inexact for some respondents. Similarly, estimates of the percentage of fresh fruit and vegetables consumed which is organic may also be inexact. On the other hand, some respondents may be mistaken about the precise nature of the policy measures to which they are subject. For example, it is possible that some respondents may not be aware that a given policy exists in their country. Similarly, some respondents may mistakenly believe that a policy exists in their country, when in fact it does not. However, it is important to note that for all questions in which there was significant potential for such "measurement error", respondents were given the option to respond that they "did not know" if such a policy was in place. This may relate to both "carrot" (i.e. grants for investment in energy-efficient devices, scrappage bounties for motor vehicles) and "stick" approaches (i.e. price-based measures). Given the large sample size, such observations should not affect the results in an important way. However, in order to ensure robustness of the results, a large number of models were estimated, including models with different country samples. Attention is drawn to important differences.

\footnotetext{
73 Australia, Canada, Chile, France, Israel, Japan, Korea, the Netherlands, Spain, Sweden and Switzerland. Approximately 1000 households were surveyed in each country.

${ }^{74}$ The first survey was carried out in 2008 in ten countries with a sample of more than 11000 respondents and the main results were presented in the OECD (2011).

75 The full 2011 EPIC Survey questionnaire in English is provided in OECD (2014) in Annex A.
} 
In general, readers should view these data as exactly what they are: the self-reported behaviours, attitudes and perceptions of representative samples of households from eleven OECD countries. Bearing the limits of such data in mind, it is important to recognise their advantages: information on households' knowledge and perceptions about environmental issues - increasingly recognised as a crucial factor for better understanding behavioural responses to environmental policies - is rarely analysed at such level of detail. Moreover, for many variables such as discrete choices about whether or not a given purchase has been made, there is likely to be very little deviation from a more formal household consumer survey. 


\section{ANNEX REFERENCES}

Brownstone, D. and R. Valletta (2001), "The Bootstrap and Multiple Imputations: Harnessing Increased Computing Power for Improved Statistical Tests", The Journal of Economic Perspectives, 15(4), 129-141.

Carlsson, F. and P. Martinsson (2004), "Willingness to Pay among Swedish Households to Avoid Power Outages - A Random Parameter Tobit Model Approach", Working Papers in Economics, No. 154 Göteborg University, Department of Economics. Retrieved from http://ideas.repec.org/p/hhs/gunwpe/0154.html

Carlsson, F. and P. Martinsson (2008), "Does it matter when a power outage occurs? - A choice experiment study on the willingness to pay to avoid power outages", Energy Economics, 30(3), 1232-1245. doi:10.1016/j.eneco.2007.04.001

Chambless, L. E. and K.E. Boyle (1985), "Maximum likelihood methods for complex sample data: logistic regression and discrete proportional hazards models", Communications in Statistics - Theory and Methods, 14(6), 1377-1392. doi:10.1080/03610928508828982

Chernozhukov, V., I. Fernández-Val and A.E. Kowalski (2011a), "Quantile Regression with Censoring and Endogeneity", Working Paper No. 16997, National Bureau of Economic Research. Retrieved from http://www.nber.org/papers/w16997

Chernozhukov, V., I. Fernández-Val and A.E. Kowalski (2011b), "Quantile Regression with Censoring and Endogeneity", Working Paper No. 16997, National Bureau of Economic Research. Retrieved from http://www.nber.org/papers/w16997

Davis, L. W. (2011), "Evaluating the Slow Adoption of Energy Efficient Investments: Are Tenants Less Likely to Have Energy Efficient Appliances?", NBER, 301-316.

Dubin, J. A. and D.L. Mc Fadden (1984), "An Econometric Analysis of Residential Electric Appliance Holdings and Consumption", Econometrica, 52(2), 345-362. doi:10.2307/1911493.

Hanemann, W.M. (1984),"Discrete/Continuous Models of Consumer Demand", Econometrica, 52(3), 541561. doi:10.2307/1913464.

Jones, A. M. (1992), "A Note on Computation of the Double-Hurdle Model with Dependence with an Application to Tobacco Expenditure", Bulletin of Economic Research, 44(1), 67.

Koenker, R. (2005), "Quantile regression", Cambridge; New York: Cambridge University Press.

Kowalski, A.E. (2009), "Censored Quantile Instrumental Variable Estimates of the Price Elasticity of Expenditure on Medical Care", Working Paper No. 15085, National Bureau of Economic Research. Retrieved from http://www.nber.org/papers/w15085 
Lumley, T. and A. Scott (2012), "Partial likelihood ratio tests for the Cox model under complex sampling", Statistics in Medicine, n/a-n/a. doi:10.1002/sim.5492.

Meng, X.-L. (1994), "Multiple-Imputation Inferences with Uncongenial Sources of Input", Statistical Science, 9(4), 538-558.

O’Garra, T. and S. Mourato (2006), "Public Preferences for Hydrogen Buses: Comparing Interval Data, OLS and Quantile Regression Approaches", "Environmental and Resource Economics", 36(4), 389411. doi:10.1007/s10640-006-9024-0.

Rao, J.N.K. and C.F.J Wu (1988), "Resampling Inference with Complex Survey Data", Journal of the American Statistical Association, 83(401), 231-241. doi:10.2307/2288945.

Reiss, P.C. and M.W. White (2005), "Household Electricity Demand, Revisited", The Review of Economic Studies, 72(3), 853-883.

Roberts, G., J.N.K. Rao and S. Kumar (1987), "Logistic Regression Analysis of Sample Survey Data", Biometrika, 74(1), 1-12. doi:10.2307/2336016

Rubin, D.B. (1996), "Multiple Imputation After 18+ Years", "Journal of the American Statistical Association, 91(434), 473-489. doi:10.2307/2291635.

Shao, J. (2003), "Impact of the Bootstrap on Sample Surveys", Statistical Science, 18(2), 191-198.

Wooldridge, J. M. (2010), "Econometric analysis of cross section and panel data", Cambridge, Mass.: MIT Press.

Yu, X. and D. Abler (2010), "Incorporating zero and missing responses into CVM with open-ended bidding: willingness to pay for blue skies in Beijing", Environment and Development Economics, 15(05), 535-556. doi:10.1017/S1355770X10000197. 